\title{
UMA ANÁLISE BIBLIOMÉTRICA DA PRODUÇÃO ACADÊMICA SOBRE O TEMA INOVAÇÃO (INNOVATION STUDIES) EM LÍNGUA PORTUGUESA
}

\begin{tabular}{lll} 
Walter Shima & $\begin{array}{l}\text { Professor do Programa de Pós-graduação em Políticas Públicas da UFPR. } \\
\text { waltershima@ufpr.br }\end{array}$ \\
\hline $\begin{array}{l}\text { Janete } \\
\text { Estevão }\end{array}$ & S. Bach & $\begin{array}{l}\text { Bibliotecária do SIBI/UFPR. Mestre e doutoranda pelo Programa de Pós-graduação } \\
\text { em Tecnologia e Sociedade da UTFPR. }\end{array}$ \\
\hline
\end{tabular}

\begin{tabular}{ll}
\hline Área 5: & Indicadores de Ciência, Tecnologia, Inovação. \\
\hline Classificação JEL: & O. Economic Development, Innovation, Technological Change, and Growth \\
& O3 Innovation, Research and Development , Technological Change, \\
& Intellectual Property Rights \\
O30 General
\end{tabular}

\section{Resumo:}

Analisa a evolução da produção acadêmica, em língua portuguesa, sobre o tema inovação. Neste contexto, a análise sobre inovação refere-se à compreensão de quais são os determinantes ambientais, econômicos e sociais do processo de surgimento e difusão da inovação. O estudo foi fortemente inspirado em Fagerberg et al (2012) e Fagerberg, J. \& Sapprasert, K. (2011) que publicaram um importante artigo sobre a relevância e crescimento dos estudos sobre inovação. Na perspectiva da língua portuguesa, a relevância decorre da necessidade de se entender em que medida essa mudança socioeconômica também se reflete no surgimento dessa nova área do conhecimento nessa língua. O artigo está organizado em três partes: explica a relevância dos Estudos sobre Inovação; trata da produção em língua portuguesa, detalha os procedimentos metodológicos utilizados na obtenção dos resultados e expõe as conclusões. Argumenta que em quase trinta anos de Estudos de Inovação no Brasil o tema já é completamente desenvolvido em praticamente todos os programas de pós-graduação das áreas de ciências sociais aplicadas, sem que haja a necessidade de formação no exterior sobre esse tema.

Palavras-chave: Estudos de inovação; Comunicação científica; Pesquisa bibliométrica.

\begin{abstract}
:
This paper analyses the evolution of the scholarly communication on Innovation studies published in Portuguese language. In this context, the analysis of innovation refers to understanding what are the environmental, economic and social determinants of the emergence and diffusion of innovation process. This study was strongly inspired by Fagerberg et al (2012) and Fagerberg, J. \& Sapprasert, K. (2011) that published an important paper about the relevance and growth of innovation studies. In Portuguese language approach, the relevance results from the need to measure how this socioeconomic change also reflects in the emergence of this new area of knowledge in that language. The paper is organized into three parts: It explains the relevance of Innovation Studies; it shows the most relevant scholarly communication in Portuguese language, it demonstrates the methodological procedures used in obtaining the results and explains the conclusions. This argues that in almost thirty years of Innovation Studies in Brazil, the subject is already completely well developed in almost all post-graduation programmes in Social Sciences Brazil, without the need for any abroad training on this subject.
\end{abstract}

Key words: Innovation studies; Scholarly communication, Bibliometric research. 


\section{UMA ANÁLISE BIBLIOMÉTRICA DA PRODUÇÃO ACADÊMICA SOBRE O TEMA INOVAÇÃO (INNOVATION STUDIES) EM LÍNGUA PORTUGUESA}

\section{Introdução}

Este artigo tem como objetivo analisar a evolução da produção acadêmica, em língua portuguesa, sobre o tema inovação. Aqui a referencia a inovação segue o sentido do que na literatura em língua inglesa denomina-se por innovation studies que tem um significado próprio, auto definido, mas que deve ser entendido como estudos que visam entender quais são os determinantes ambientais, econômicos e sociais do processo de surgimento e difusão da inovação. Inovação aqui, portanto, é vista como um resultado de uma conjunção de elementos tecnológicos, concorrenciais, institucionais e sociais e não exclusivamente como decorrente de um processo laboratorial/experimental que leva em conta apenas aspectos materiais técnicos. Desse modo, buscando enfatizar e diferenciar o sentido da inovação aqui estudado, na medida da necessidade semântica, será usado o termo em inglês ou traduzido, Estudos sobre Inovação.

O estudo foi fortemente inspirado em Fagerberg et al (2012) e Fagerberg, J. \& Sapprasert, K. (2011) que publicaram um importante artigo sobre a relevância e crescimento dos Estudos sobre Inovação. Na medida da disponibilidade dos dados para a língua portuguesa foram feitos levantamentos semelhantes aos feitos nesse artigo, de forma a se ter uma base de comparação. Percebe-se que nas duas línguas o tema assumiu relevância crescente nos últimos anos tendendo a ser mais publicado na abordagem de Estudos sobre Inovação do que em outras áreas, no sentido exclusivamente tecnológico. Nesse sentido, busca-se aqui avaliar em que medida as pesquisas sobre este tema têm assumido relativamente o mesmo grau de relevância do que na língua inglesa. Obviamente isso é relativo, em função de que, o volume editorial em língua portuguesa é muito inferior, o que já é amplamente sabido em todas as áreas do conhecimento. A crença inicial é que somente a partir da segunda metade da década de 80 é que se descobre efetivamente essa nova área de pesquisa na língua portuguesa. Em suma, buscase responder a: qual é a relevância que os Estudos sobre Inovação assumiram nas publicações em língua portuguesa? Segundo os autores acima esta pesquisa é relevante por considerar que as ciências sociais é uma estrutura em constante evolução, desafiada por novos problemas e consequentemente necessita novos conhecimentos. Na medida em que novos conhecimentos são gerados, novos desafios são colocados por uma sociedade em mudança permanente. Desse modo, as novas abordagens dentro das ciências sociais são exemplos de como novas áreas do conhecimento surgem e gradualmente se consolidam como tema importante de pesquisa. Os Estudos sobre Inovação são exatamente uma nova área do conhecimento reflexo da mudança social e econômica. Eles se tornam relevante em um momento em que há uma quebra da dinâmica econômica a partir de uma profusão de ondas inovadoras na economia, marcadamente pela microeletrônica, biotecnologia, novos materiais, química fina, etc. Ou seja, o tema inovação surge a partir do momento em que a sociedade se defronta com novos desafios organizacionais e produtivos dentro das condições de rompimento do estado estacionário descrito por Schumpeter. Daí a necessidade de se estudar a inovação no sentido aqui definido. Na perspectiva da língua portuguesa a relevância decorre da necessidade de se entender em que medida essa mudança socioeconômica também se reflete no surgimento dessa nova área do conhecimento nessa língua. Ademais, como será visto, o início dos Estudos sobre Inovação no Brasil é marcado pela formação de professores da UFRJ no SPRU/SUSSEX, caracterizando um processo de formação de multiplicadores dessa nova área de conhecimento no país. Tratava-se de uma caixa-preta ainda desconhecida sendo aberta por aqueles ainda em período de formação e que trariam o novo conhecimento. Depois de quase trinta anos de Estudos de Inovação no Brasil o tema já é completamente desenvolvido em praticamente todos os programas de pós-graduação das áreas de ciências sociais aplicadas, sem que haja a necessidade de formação no exterior sobre esse tema.

O artigo está dividido em três partes além desta Introdução. A segunda explica a relevância dos Estudos sobre Inovação; a terceira trata da produção em língua portuguesa, explica os procedimentos metodológicos utilizados e mostra os resultados e a quarta expõe as conclusões. 


\section{A Relevância dos Estudos sobre Inovação}

Fagerberg et al (2012) publicaram um importante artigo sobre a relevância e crescimento dos estudos sobre inovação. Nesse artigo os autores revisaram as publicações mais referenciadas sobre questões de inovação e avaliaram a produção acadêmica sobre elas. De acordo com a GRÁFICO 1 de Fagerberg\& Verspagen (2009) ${ }^{1}$ citado por Fagerberg et al (2012) verifica-se que esse campo do conhecimento tem crescido rapidamente nos anos recentes e muitos acadêmicos ao redor do mundo estão pesquisando atualmente sobre esse tema.

\section{GRÁFICO 1- CRESCIMENTO DA LITERATURA SOBRE INOVAÇÃO}

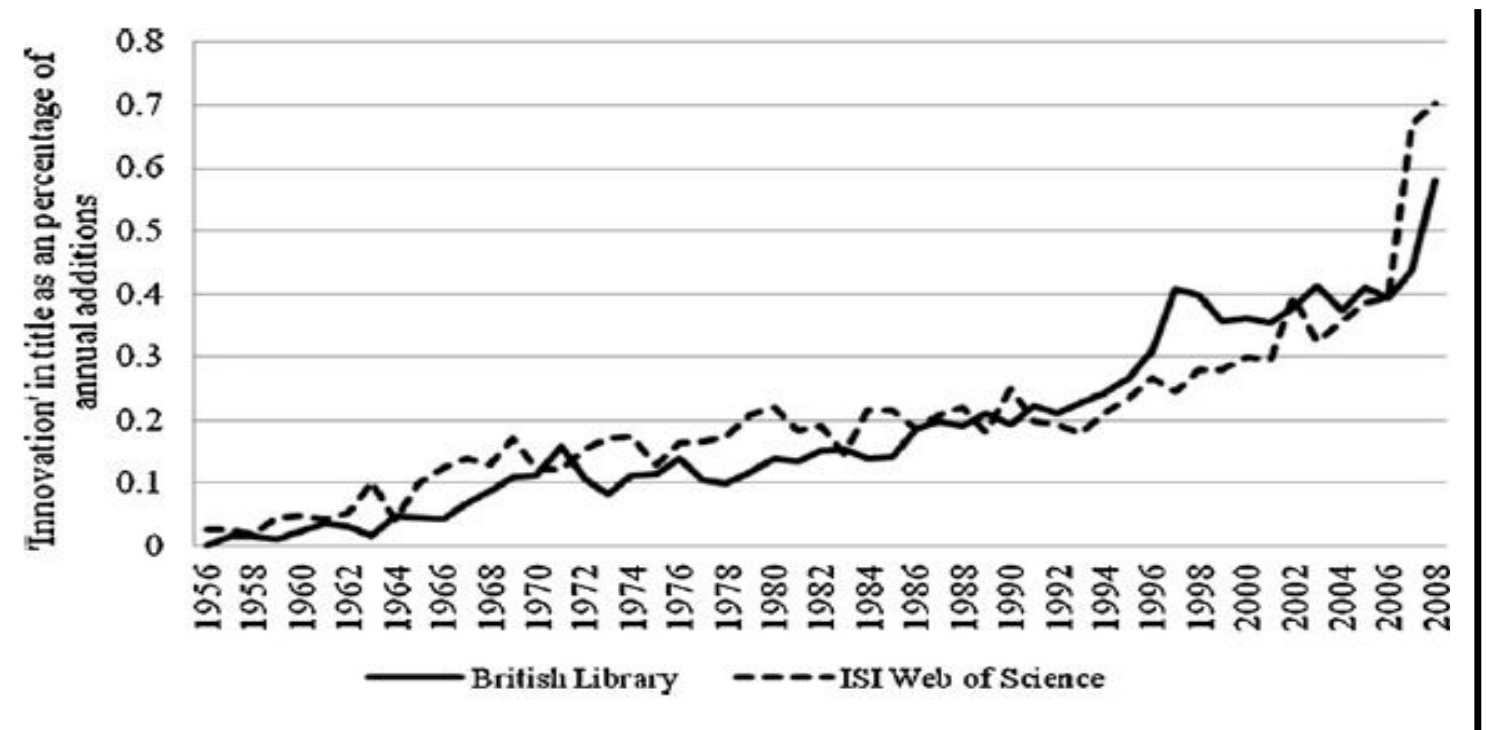

FONTE: Fagerberg, J., Verspagen, B., 2009 em Fagerberg et al (2012)

Fagerberg et al (2012) também demonstram no GRÁFICO 2 que a palavra inovação no titulo das publicações tem crescimento rapidamente desde os anos 60 e principalmente nos anos 90 . Como se nota 0 interesse acadêmico por Estudos sobre Inovação é relativamente recente. No inicio do século XX o único autor que tratou de inovação como uma força dinâmica que causa contínuas transformações da estrutura social, institucional e econômicas e consequentemente supôs que os agentes sociais conduzem o desenvolvimento econômico, foi Schumpeter nos livros A Teoria do Desenvolvimento Econômico (1912/1934) e Capitalismo, Socialismo e Democracia (1942) e é exatamente a partir da II Grande Guerra que houve uma atenção importante a inovações a partir dos formuladores de políticas para alavancar as tecnologias militares e logo após as tecnologias civis. Numa perspectiva acadêmica as primeiras publicações nas áreas de Economia, Administração e Sociologia estão no QUADRO 1.

QUADRO 1 - PRIMEIRAS PUBLICAÇÕES SOBRE INNOVATION STUDIES

\begin{tabular}{|l|l|}
\hline \multirow{5}{*}{ Economia } & $\begin{array}{l}\text { Nelson, R.R., 1959. The simple economics of basic scientific research. Journal of Political Economy 67, } \\
\text { 297-306. }\end{array}$ \\
\cline { 2 - 3 } & Schmookler, J., 1966. Invention and Economic Growth. Harvard University Press, Massachusetts \\
\cline { 2 - 2 } & $\begin{array}{l}\text { Arrow, K., 1962. Economic welfare and the allocation of resources for invention. In: Nelson, R.R. } \\
\text { (Ed.), The Rate and Direction of Inventive Activity: Economic and Social Factors. Princeton } \\
\text { University, Princeton. }\end{array}$ \\
\hline \multirow{2}{*}{ Administração } & Burns, T., Stalker, G., 1961. The Management of Innovation. Tavistock, London. \\
\hline \multirow{2}{*}{ Sociologia } & Rogers, E.M., 1962. Diffusion of Innovations. The Free Press, New York. \\
\cline { 2 - 2 } & Coleman, J.S., Katz, E.,Menzel, H., 1966. Medical Innovation. Boobs-Merril, New York. \\
\hline
\end{tabular}

FONTE: Fagerberg, J. \& Sapprasert, K. (2011) 
GRÁFICO 2 - CRESCIMENTO DE PUBLICAÇÕES CUJO TITULO TINHA A PALAVRA INOVAÇÃO - 1960-2006 - \% DE TODAS AS PUBLICAÇÕES.

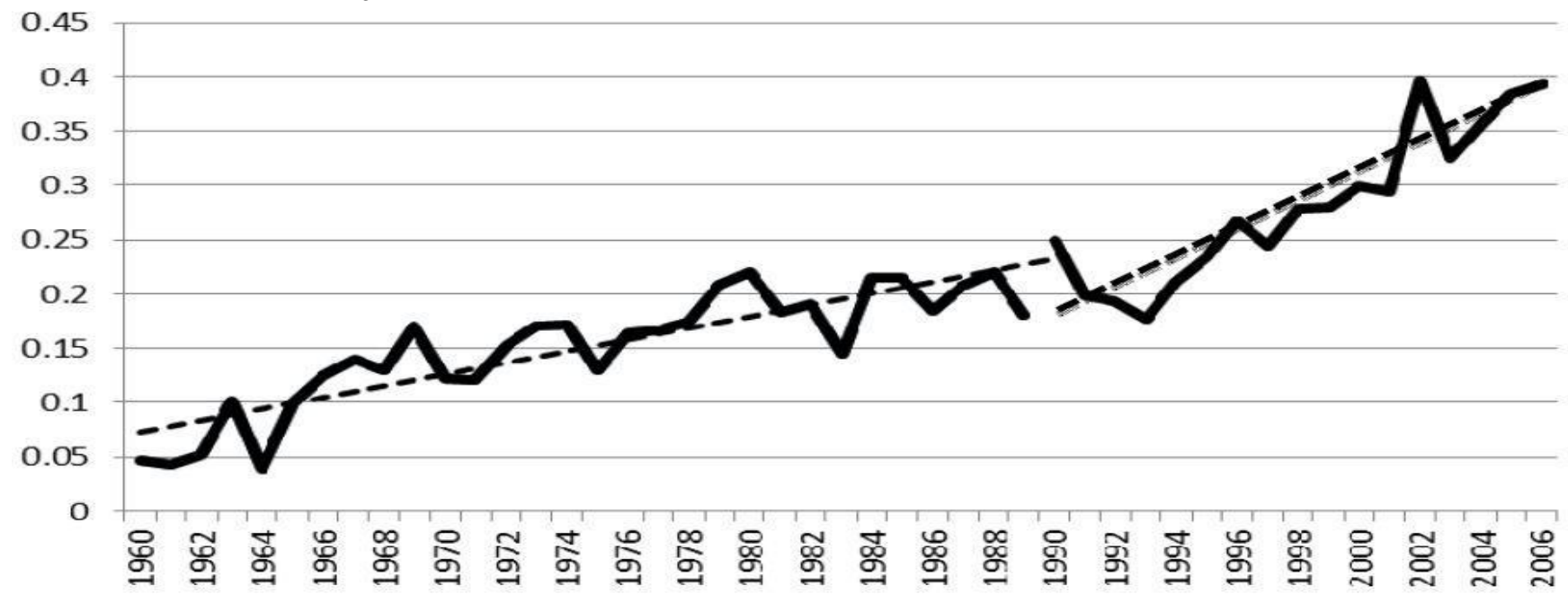

FONTE: Fagerberg, J. \& Sapprasert, K. (2011)

Segundo Fagerberg et al. (2012), antes dos anos 70 a principal característica destas contribuições era a falta de interações entre elas em termos de objeto. Afirmam que Rogers (1961) refere-se a sociologia rural americana; Burns \& Stalker (1962) é uma tentativa prematura de produzir um manual sobre gestão de inovação e Arrow (1962) é uma perspectiva tradicional sobre a alocação de recursos para $P \& D$. Os fundamentos básicos sobre inovação são diferentes entre eles, uma vez que, são as primeiras produções acadêmicas sobre esse tema. Ao mesmo tempo, começa haver um importante interesse por parte de pesquisadores sobre inovação (no sentido de Estudos sobre Inovação) vindo do setor privado em função do relacionamento feito por acadêmicos. O Professor Richard Nelson - junto com o Professor Sidney Winter um dos autores mais difundidos no Brasil nos Estudos sobre Inovação com o livro Uma Teoria Evolucionária da Mudança Econômica, publicado em português em 2005 pela Editora Unicamp ${ }^{2}$ - trabalhava para a RAND Corp. enquanto desenvolvia a Economia da P\&D. Christofer Freeman - junto com Luc Soete, autores do também clássico livro A Economia da Inovação Industrial, publicado em português em 2008 pela Editora Unicamp - trabalhava num instituto de pesquisa privada mantida pela indústria britânica e pesquisava a dinâmica de $P \& D$ dentro das firmas britânicas. Também é importante mencionar o NBER (National Bureau for Economic Research), nos EUA e Europa, como uma das primeiras instituições a financiar pesquisa sobre P\&D em economia. Portanto, ao longo do tempo desenvolveu-se uma nova área importante para pesquisas na área das ciências humanas e sociais com um expressivo volume de publicações e surgiram muitas referencias mundiais de produção acadêmica sobre inovação.

\subsection{O Procedimento de Pesquisa de Fageberg et al. (2012)}

Especificamente, a pesquisa bibliométrica conduzida pelos autores consistiu no que se segue. Por meio de diversas buscas na internet das publicações mais referenciadas, os autores identificaram 11 mais importantes manuais (QUADRO 2) sobre questões de inovação que compreendem 277 capítulos com abordagens diferentes.

QUADRO 2 - OS 11 MANUAIS SOBRE O TEMA INOVAÇÃO

\begin{tabular}{|l|l|l|l|}
\hline $\mathbf{N}^{\mathbf{o}}$ & \multicolumn{1}{|c|}{ Autores } & Titulo & \multicolumn{1}{c|}{ Assunto } \\
\hline 1 & Cozijnsenand Vrakking (1993) & Handbook of Innovation & Organização e administração \\
\hline
\end{tabular}

\footnotetext{
${ }^{2}$ A iniciativa da Editora Unicamp de traduzir 9 livros clássicos sobre Estudos de Inovação a partir de 2008 - denominada Coleção Clássicos da Inovação - é mais um indicativo da relevância que o tema assumiu na língua portuguesa e também ressalta o papel da Unicamp como precursora no tema (como será visto adiante no texto) Ver http://www.editoraunicamp.com.br/produtos.asp?id=80.
} 


\begin{tabular}{|c|c|c|c|}
\hline 2 & Poole and Van de Ven (2004) & $\begin{array}{l}\text { Handbook of Organisational Change } \\
\text { and Innovation }\end{array}$ & \\
\hline 3 & Shane (2008) & $\begin{array}{l}\text { Handbook of Technology and } \\
\text { Innovation }\end{array}$ & \\
\hline 4 & Dodgson and Rothwell (1994) & Handbook of Industrial Innovation & \multirow{3}{*}{$\begin{array}{l}\text { Uma orientação geral visando cobrir o } \\
\text { máximo da literatura relevante. }\end{array}$} \\
\hline 5 & Shavinina (2003) & International Handbook on Innovation & \\
\hline 6 & Fagerberg et al. (2004) & The Oxford Handbook of Innovation & \\
\hline 7 & Hall and Rosenberg (2010) & $\begin{array}{l}\text { Handbook of the Economics of } \\
\text { Innovation Economics of Innovation }\end{array}$ & \multirow{2}{*}{ Economia da inovação } \\
\hline 8 & Stoneman (1995) & $\begin{array}{l}\text { Handbook of the Economics of } \\
\text { Innovation and Technological Change }\end{array}$ & \\
\hline 9 & Karlsson (2008) & $\begin{array}{l}\text { Handbook of Research on Innovation } \\
\text { And Clusters }\end{array}$ & Aspectos espaciais da inovação \\
\hline 10 & Lundvall et al. (2009) & $\begin{array}{l}\text { Handbook of Innovation Systems and } \\
\text { Developing Countries }\end{array}$ & Inovação e desenvolvimento \\
\hline 11 & Galloujand Djellal (2010) & $\begin{array}{l}\text { The Handbook of Innovation and } \\
\text { Services }\end{array}$ & Inovação em serviços \\
\hline
\end{tabular}

FONTE: Fagerberg et al. (2012)

Desses 11 manuais as 20 contribuições mais citadas dentro dos 277 capítulos estão no QUADRO 3.

QUADRO 3 - AS TOP 20 CONTRIBUIÇÕES MAIS CITADAS NOS 11 PRINCIPAIS MANUAIS

\begin{tabular}{|c|c|c|c|c|c|}
\hline $\mathbf{N}^{\mathbf{0}}$ & Autor & País & Titulo & Tipo & Ano \\
\hline 1 & $\begin{array}{l}\text { Nelson R \& Winter } \\
\text { S }\end{array}$ & \multirow{3}{*}{ EUA } & An Evolutionary Theory of Economic Change & \multirow{7}{*}{ Livro } & 1982 \\
\hline 2 & Nelson RR & & National Innovation Systems & & 1993 \\
\hline 3 & Porter ME & & The Competitive Advantage of Nations & & 1990 \\
\hline 4 & Schumpeter JA & $\begin{array}{l}\text { Áustria/ } \\
\text { EUA }\end{array}$ & The Theory of Economic Development & & $\begin{array}{l}1912 / \\
1934 \\
\end{array}$ \\
\hline 5 & Rogers EM & EUA & Diffusion of Innovations & & 1962 \\
\hline 6 & LundvallB-Å & Dinamarca & $\begin{array}{l}\text { National Innovation Systems-Towards a Theory of } \\
\text { Innovation and Interactive Learning }\end{array}$ & & 1992 \\
\hline 7 & Freeman C & RU & The Economics of Industrial Innovation & & 1974 \\
\hline 8 & $\begin{array}{l}\text { Cohen W \& } \\
\text { Levinthal D }\end{array}$ & EUA & Absorptive Capacity & \multirow[t]{2}{*}{ Artigo } & 1990 \\
\hline 9 & Pavitt K & RU & Sectoral Patterns of Technical Change & & 1984 \\
\hline 10 & Arrow K & \multirow{2}{*}{ EUA } & $\begin{array}{l}\text { Economic Welfare and Allocation of Resources for } \\
\text { Invention }\end{array}$ & $\begin{array}{l}\text { Capítulo de } \\
\text { livro }\end{array}$ & 1962 \\
\hline 11 & Saxenian A & & Regional Advantage: & \multirow{4}{*}{ Livro } & 1994 \\
\hline 12 & Freeman C & RU & $\begin{array}{l}\text { Technology Policy and Economic Performance: } \\
\text { Lessons from Japan }\end{array}$ & & 1987 \\
\hline 13 & von Hippel E & \multirow{7}{*}{ EUA } & The Sources of Innovation & & 1988 \\
\hline 14 & Christensen C & & The Innovator's Dilemma & & 1997 \\
\hline 15 & Teece DJ & & Profiting From Technological Innovation & Artigo & 1986 \\
\hline 16 & $\begin{array}{lcl}\text { Kline } \quad \mathrm{S} & \& \\
\text { Rosenberg } & \mathrm{N} & \\
\end{array}$ & & An Overview of Innovation & $\begin{array}{l}\text { Capítulo de } \\
\text { livro }\end{array}$ & 1986 \\
\hline 17 & $\begin{array}{lll}\text { Henderson } & \mathrm{R} & \& \\
\text { Clark K } & & \\
\end{array}$ & & Architectural Innovation & Artigo & 1990 \\
\hline 18 & Rosenberg $\mathrm{N}$ & & Inside the Black Box & \multirow{3}{*}{ Livro } & 1982 \\
\hline 19 & Schumpeter JA & & Capitalism, Socialism and Democracy & & 1942 \\
\hline 20 & $\begin{array}{l}\text { Tidd J; Bessant J; } \\
\text { Pavitt K }\end{array}$ & RU & Managing Innovation & & 1997 \\
\hline
\end{tabular}

FONTE: Fagerberg et al. (2012)

2.1.1 As Principais Abordagens e Conceitos Inovadores nas Ciências Econômicas a partir desses Autores

Consideradas juntas essas 20 referências cobrem um amplo espectro de tópicos relevantes sobre inovação. Em geral, essas pesquisas abordam 3 temas: 1) inovação dentro firma, focando em negócios e 
gestão; 2) mudança econômica e social, focando em economia e ciências sociais e 3) mudança setorial, focando no relacionamento entre agentes econômicos e sociais de vários setores e refere-se a uma abordagem intermediaria entre firma e mudança econômica. De acordo com Fagerberg et al. (2012) de todas essas contribuições a mais importante vem de Nelson \& Winter (1982). Esse livro foca na combinação de abordagem schumpeteriana, teoria da organização e comportamento humano para desenvolver uma teoria sobre o conhecimento intra-firma, suas estratégias e resultados. Sendo uma ampla alternativa teórica à teoria econômica tradicional, os autores afirmam que esta última é baseada num ponto de vista completamente irreal sobre o comportamento humano. Os seres humanos não são habilitados a calcular as consequências e todas as possíveis ações e escolher a melhor delas como os economistas costumam supor. O mundo é muito complexo e o volume de informações é amplo e as capacidades cognitivas dos humanos e organizações são muito limitadas para tomar essas decisões. Na realidade, as firmas adotam um mecanismo menos exigente de decisão baseado em rotinas que são reproduzidas e modificadas ao longo da prática e são armazenadas na memória ou conhecimento organizacional. Estas são as prevalecentes rotinas técnicas, de produção, contratos, estratégias, marketing, contratações, $P \& D$, vendas, etc. Rotina se relaciona ao gene enquanto as firmas se comportam hoje de acordo com suas decisões ou práticas advindas do passado.

No final dos anos 80 uma nova abordagem holística surgiu com Nelson (1993), Lundval (1992), Freeman (1987) na perspectiva de Sistema Nacional de Inovação (SNI). Influenciada pela OCDE esta perspectiva aponta o papel desempenhado pelas políticas, governança e instituições para a inovação. Freeman afirma que SNI é uma rede de instituições no setor público e privado cujas atividades e interações começam, mudam e disseminam novas tecnologias. Essa primeira ideia foi exposta no livro Technology Policy and Economic Performance: Lessons from Japan (1987), sobre o SNI japonês. Dentro da perspectiva schumpeteriana Freeman viu o crescimento econômico como resultado de inovações e difusão de tecnologias. Diferente de Schumpeter, Freeman estava interessado nas habilidades das diferentes nações pra explorar inovação em seu próprio beneficio e que poderia ser apoiado por políticas. A palavra sistema se refere a fatores nacionais que explicariam as diferenças entre países. Numa abordagem mais estrita Lundvall estava interessado em inovações como um processo interativo entre usuários e produtores dentro do SNI. Essa abordagem foi exposta no livro Towards a Theory of Innovation and Interactive Learning (1992).De acordo com Metcalfe o SNI é um conjunto de instituições distintas que conjunta e individualmente contribuem para o desenvolvimento e difusão de novas tecnologias ademais de prover uma estrutura dentro do qual o governo formula e implementa políticas para influenciar o processo de inovação. Como tal, o SNI é um sistema de instituições interconectadas para criar, armazenar e transferir conhecimento, habilidades e artefatos que definem novas tecnologias. A mesma abordagem pioneira está no livro de Nelson (1993). National Innovation Systems: A Comparative Study.

Numa perspectiva diferente, mais localizada nos setores industriais Pavitt (1984 e 1994) estabelece empiricamente uma taxonomia de atividades de inovação em diferentes setores e indústrias. O objetivo é explicar o padrão setorial da mudança técnica baseada em 2000 maiores inovação lançadas desde 1945. Dada a complexidade tecnológica das firmas elas seguiriam a seguinte taxonomia:

- São firmas originárias de setores tradicionais de manufatura, agricultura, construção, produção informal e vários tipo de serviços comerciais.

Firmas Dominadas • Geralmente firmas pequenas com fraco processo de P\&D.

pelos Fornecedores: - Trajetória tecnológica baseada em redução de custo.

- A maioria das inovações vem dos fornecedores de equipamentos e materiais.

- Eventualmente, grandes clientes e governos financiam a P\&D.

- Divide-se em dois tipos:

- Intensivo em escala: são os produtores de matéria-prima, siderurgia, bens de consumo durável. São sensíveis a preço e geralmente são grandes firmas.

Firmas de Produção Intensiva:

- Fornecedor especializado: são os fabricantes de maquinaria e instrumentos e trabalha mais no desenvolvimento de usuários e montagem de maquinas.

- A característica geral é alta divisão do trabalho, trajetória tecnológica focada em aumento de escala, produtos padronizados e produção em massa. . 


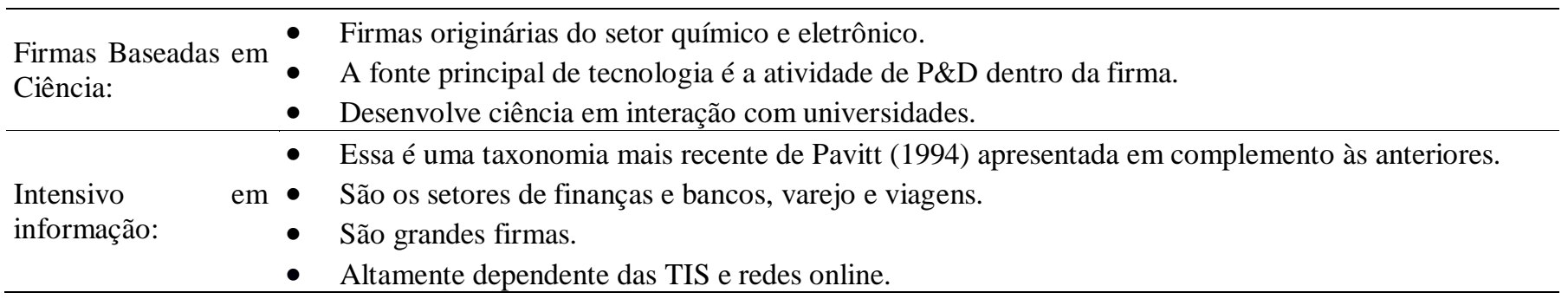

Outra abordagem sobre inovação também bastante holística é a de Dosi (1982) com a ideia de paradigma e trajetórias tecnológicas. Especificamente o autor destaca que a tecnologia em um dado momento do tempo pertence a um conjunto limitado de várias possibilidades tecnológicas atuais que visam futuros avanços. Portanto, uma tecnologia incorpora um conjunto de conhecimentos que pertence a um dado paradigma tecnológico. Um paradigma tecnológico significa um modelo ou uma solução padrão para problemas tecnológicos selecionados com base em princípios selecionados derivados das ciências naturais e tecnologias de materiais selecionados. Seleção tem a ver com a escolha de uma forma de resolver os problemas dentro de várias possibilidades dentro de um determinado paradigma tecnológico. Esta seleção é definida devido a um conjunto de variáveis econômicas e tecnológicas anteriores. Um paradigma tecnológico fornece normas fortes sobre a direção da mudança técnica que deve ser procurada e também negligenciada.

Para Freeman \& Perez (1988) o paradigma tecnológico é uma das taxonomias da inovação compreendida por:

1) Inovações incrementais: ocorre mais ou menos continuamente em qualquer indústria ou atividade de serviço com diferentes taxas dependendo da combinação entre pressões de demanda, fatores socioculturais e oportunidades tecnológicas. É o resultado de P\&D deliberado, mas também de invenções e melhorias sugeridas por engenheiros e outros diretamente envolvidos diretamente no processo produtivo.

2) Inovações radicais: são eventos descontínuos e resultam de $P \& D$ deliberado em universidades, empresas e laboratórios de governo. São inovações distribuídas de forma desigual em diversos setores ao longo do tempo.

3) Mudanças de sistemas tecnológicos: são mudanças tecnológicas de longo alcance afetando vários ramos da economia, assim como permite o surgimento de novos setores. São combinações de inovações radicais e incrementais junto com inovações organizacionais e gerenciais. Surge uma constelação de inovações técnica e economicamente inter-relacionadas.

4) Mudanças de paradigma técno-econômico: esse corresponde ao mesmo conceito de Dosi visto acima. São mudanças tecnológicas de tão longo alcance que influenciam o comportamento de todo a economia e traz consigo um conjunto de inovações radicais e incrementais e quantidade significativa de novos sistemas tecnológicos. A característica vital são os efeitos pervasivos ao longo de toda a economia.

Na medida em que as novas tecnologias são propagadas há um período prolongado de crescimento econômico com lucros elevados e aumento da produtividade. Mas, gradualmente, na medida em que o conjunto de aplicações é mais ou menos concluído e através de sucessivas melhorias incrementais as fronteiras das melhores práticas são alcançadas, as forças que determinam as ondas de prosperidade diminuem. Os limites para o crescimento são encontrados em mais e mais setores da economia, os lucros diminuem e o aumento da produtividade é reduzido. Neste momento, há uma longa onda de fusões e aquisições, várias formas de especulação e esforços para substituir o trabalho por capital, enquanto há uma busca persistente de um conjunto viável de tecnologias que podem ser promissores em termos de lucro. No paradigma econômico, há uma nova regra: redução permanente de custos (custos relativos seguem uma tendência previsível no conjunto da economia; oferta ilimitada; influência potencial da tecnologia dominante em todos os setores econômicos que muda qualitativamente os equipamentos, processo de trabalho, gestão, etc.).

Essa abordagem, nessa época, já indicava o fato que a partir dos anos 90 houve uma grande mudança no assunto pesquisado pelos Estudos sobre Inovação. Eles passaram do foco na firma e setor para o conjunto da economia, com foco nas instituições e políticas, como mecanismo de difusão da 
inovação. Freeman foi o autor mais importante responsável por essa mudança de foco decorrente da sua perseverança na ideia de que a inovação deve ser vista desde uma perspectiva sistêmica. Por exemplo, o GRÁFICO 3mostra o número de novos artigos publicados entre 1996 e 2008 com a combinação de palavras inovação e sistema, inovação e indústria e inovação e firma no título. O resultado claramente confirma que a literatura sobre sistema cresceu mais rapidamente que as outras combinações confirmando a abordagem mais holística nos estudos sobre inovação (Fagerberg et al., 2012).

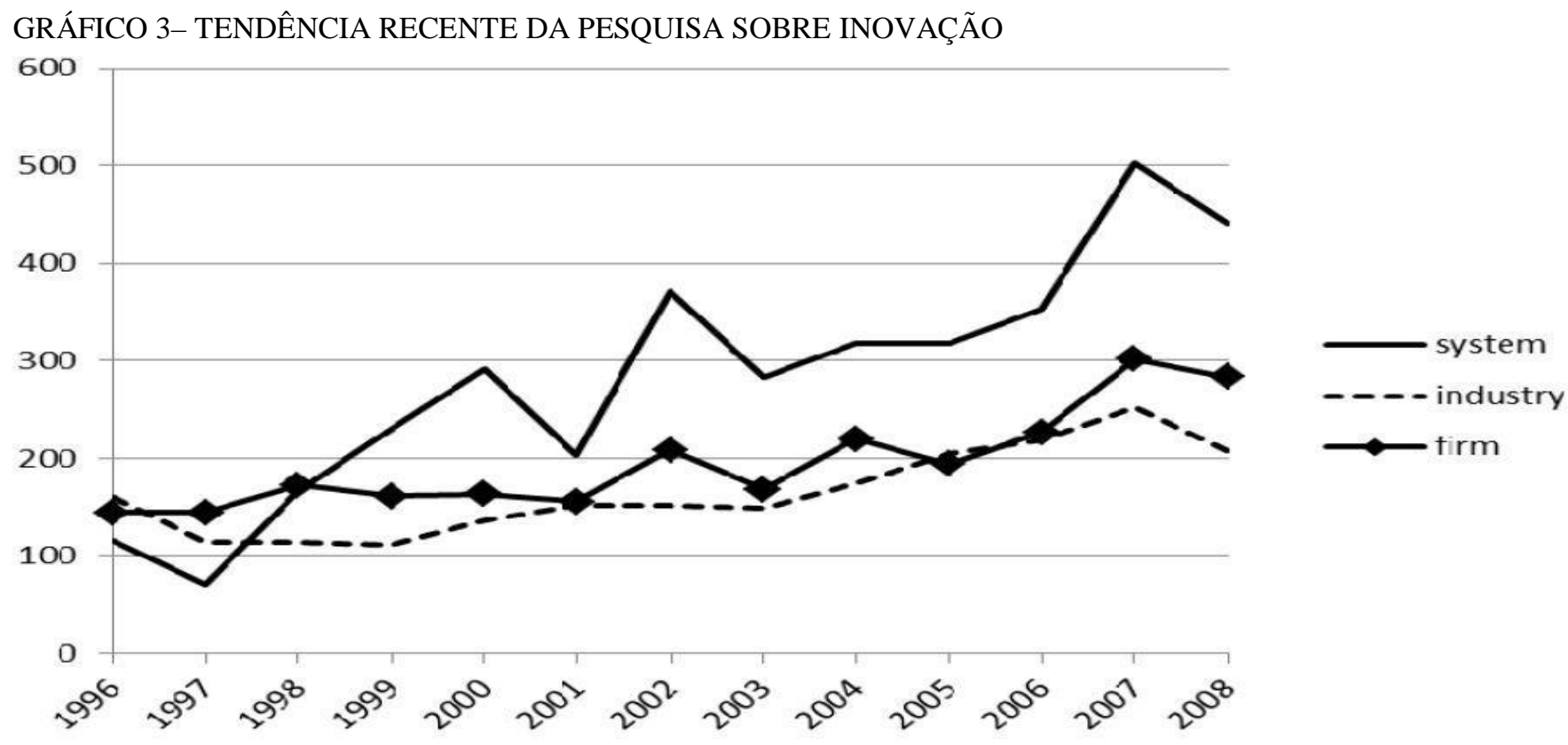

FONTE: Fagerberg, J. \& Sapprasert, K. (2011)

O GRÁFICO 4 apresenta as top 10 instituições baseadas na importância das contribuições das suas pesquisas. As mais influentes são as universidades top americanas e apenas uma européia (SPRU) que é a casa de acadêmicos influentes como Freeman, Pavitt e inicialmente Dosi e rivaliza com as mais bem financiadas concorrentes americanas. Destaque deve ser dado à $10^{\mathrm{a}}$ colocada que é a Aalborg University, casa de Bengt-ÅkeLundvall, que entre outros assuntos contribuiu de forma relevante para difundir a abordagem do sistema nacional de inovação (Fagerberg et al., 2012).

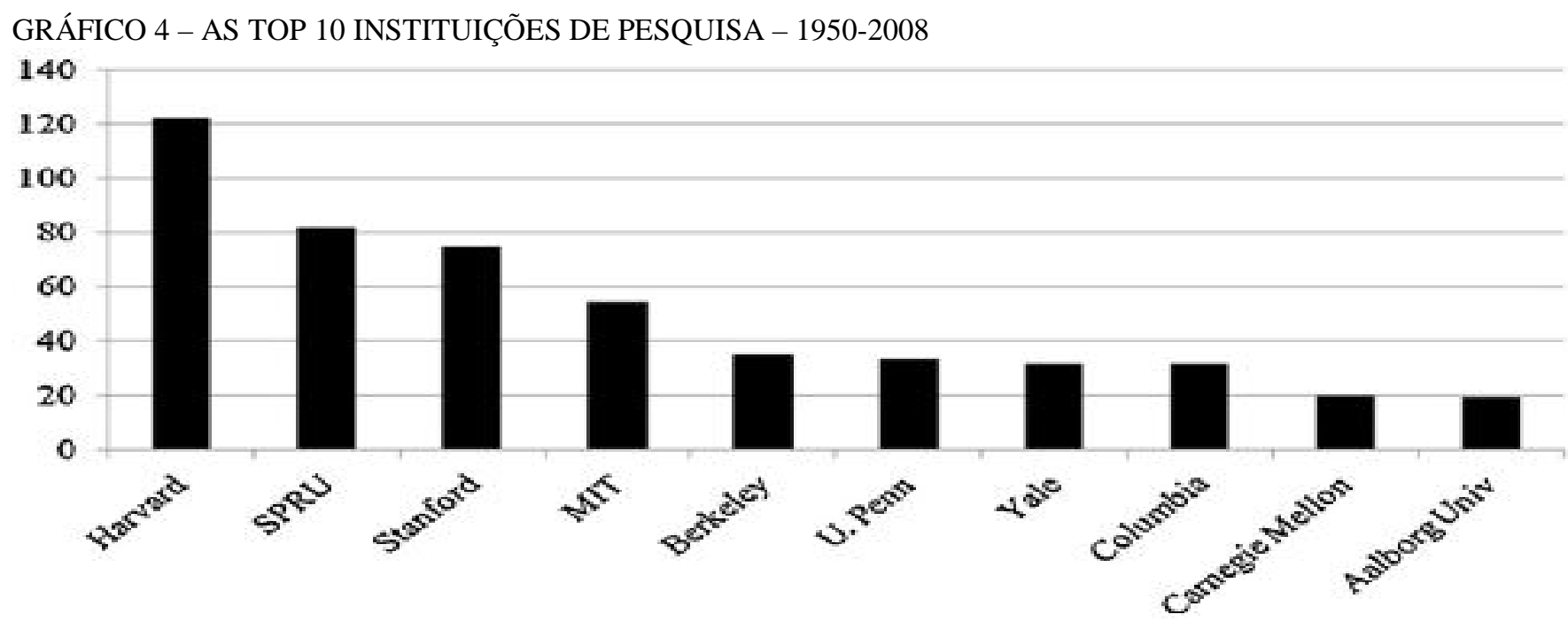

FONTE: Fagerberg et al. (2012)

\section{A Produção Acadêmica em Língua Portuguesa sobre Innovation Studies}

Os artigos Fagerberg et al. (2012) e Fagerberg, J. \& Sapprasert, K. (2011) amplamente referenciados acima despertaram a mesma pergunta sobre as publicações sobre o tema inovação em 
língua portuguesa. Ou seja, qual é a relevância que o tema inovação assumiu na língua portuguesa? Desse modo, foi feito um levantamento bibliométrico dos Estudos sobre Inovação nessa língua com o objetivo de se ter alguma comparação com as publicações em língua inglesa. É importante fazer este tipo de estudo uma vez que, este tema tem sido relevante em língua inglesa justamente em função da permanente mudança tecnológica recente (desde quando começaram a crescer o numero de publicações nos anos 80/90 em língua inglesa) que crescentemente tem causado mudanças sociais e econômicas. Nesse sentido, busca-se aqui avaliar em que medida as pesquisas sobre este tema têm assumido relativamente o mesmo grau de relevância do que na língua inglesa. Obviamente isso é relativo, em função de que, o volume editorial em língua portuguesa é muito inferior, o que já é amplamente sabido em todas as áreas do conhecimento. A crença inicial é que somente a partir da segunda metade da década de 80 é que se descobre efetivamente essa nova área de pesquisa na língua portuguesa.

Para este estudo os levantamentos feitos não puderam seguir o mesmo procedimento dos autores citados acima. Eles trabalharam amplamente em buscas na Web of Science que é uma base de subscrições cientificas que indexa a maior parte das bases de publicações relevantes mundiais de todas as áreas. No caso das publicações em português as buscas foram feitas no:

1) Portal de Periódicos da Coordenação de Aperfeiçoamento de Pessoal de Nível Superior (CAPES) que é uma fundação ligada ao Ministério da Educação.

2) No serviço de informação Ebscohost e

3) Na biblioteca eletrônica SciELO.

\subsection{A Relevância do Portal de Periódicos/CAPES}

O Portal é uma biblioteca virtual que reúne e disponibiliza às Instituições de Ensino Superior (IES) no Brasil o melhor da informação científica e tecnológica internacional. Na sua inauguração, em novembro de 2000, o Portal contava com 1.800 títulos com textos completos e 14 bases de dados referenciais, atendendo cerca de 80 IES (Santana et al. 2012, 133; Brasil, 2008; Correa et al. 2008, 134;137). Ao longo dos anos, essa comunicação foi sendo feita com os recursos disponíveis em cada momento da história nacional. Passados 16 anos, este portal tornou-se a maior rede de consórcio do mundo, atendendo mais de 424 IES públicas e privadas no Brasil, centros de pesquisa, órgãos do governo federal brasileiro, por meio do acesso democrático e simultâneo, registrando em 2013 mais de 100 milhões de acesso, financiado 100\% pelo Governo, a um custo de R\$ 173.900,000 (nesse ano) (Brasil, 2013a,b). Trata-se de um instrumento de altíssima relevância dentro da função da CAPES que é a formação de recursos humanos qualificados, pela expansão e consolidação da pós-graduação stricto sensu em todos os estados brasileiros ${ }^{3}$. Em outros termos, é mais uma ferramenta de capacitação da comunidade acadêmica na utilização do acervo (Brasil, 2015a).

O acesso livre e gratuito ao conteúdo do Portal de Periódicos é disponibilizado para toda a comunidade acadêmica vinculada às instituições que participam. Para participar, a Instituição deve ser elegível de acordo com os critérios estabelecidos pela Capes, como por exemplo: Instituições federais de ensino superior; Instituições de pesquisa e Instituições públicas de ensino superior (estaduais e municipais), com pelo menos um programa de pós-graduação, que tenha obtido nota 4 ou superior na avaliação da Capes e instituições privadas de ensino superior, com pelo menos um doutorado, que tenha obtido nota 5 ou superior na avaliação da Capes. Outra modalidade de acesso foi disponibilizada para aquelas instituições que não atendem aos critérios citados, porém pagam para acessar determinadas bases do Portal e se beneficiam da economia obtida pela negociação da Capes junto aos editores (Brasil, 2015b). Por último, há ainda a possibilidade de acesso gratuito, sem qualquer pré-requisito, às bases de dados nacionais e internacionais, referências de teses e dissertações produzidas nos programas de pósgraduação de todo o Brasil e periódicos brasileiros com uma boa avaliação no programa Qualis-Capes ${ }^{4}$.

3 A atuação da Capes se dá por um conjunto estruturado de programas nacionais para a avaliação dos cursos de pós-graduação stricto sensu, acesso e divulgação da produção científica, realização de investimentos na formação de recursos de alto nível no país e exterior, promoção da cooperação científica internacional e indução e fomento da formação inicial e continuada de professores para a educação básica nos formatos presencial e a distância (Brasil, 2008).

4 É possível realizar buscas rápidas por assunto, títulos de periódico, bases de dados e livros eletrônicos, além de ler e exportar artigos em formato PDF para o dispositivo (Brasil, 2015c). Em relação ao suporte às bibliotecas universitárias, a Capes coloca a disposição uma equipe 


\subsection{A Relevância do Portal Ebscohost}

O Portal EBSCOHost é um dos serviços da EBSCOInformation Services que opera os serviços de informação do grupo empresarial EBSCO Industries ${ }^{5}$. Esta subsidiária é o principal fornecedor de recursos para bibliotecas em todo o mundo. O Portal EBSCOhost é o primeiro serviço de pesquisa gratuito online no mundo, incluindo bases de dados de texto completo, índices de assunto, materiais médicos de referência, arquivos digitais históricos e e-books. Oferece também seus serviços a bibliotecas com mais de 8.000 clientes em mais de 100 países. (COMPANY, 2016). Dentre os serviços da EBSCOInformation Services, destacam-se: Serviço de descoberta EBSCO (EDS); Bases de dados de pesquisa; eBooks e audiobooks; Serviços de Journals e Empacotamento eletrônico; Métricas de pesquisa da PlumAnalytics; Arquivos digitais e Recursos de aprendizagem e de formação de organização.

As bases de dados disponíveis pelo portal Ebscohost na UFPR - onde foram feitos os levantamentos - são de acesso restrito e estão disponíveis a toda comunidade universitária. Podem ser acessadas por IP em qualquer computador na universidade ou via conexão doméstica para usuários que possuam e-mail institucional cadastrado. As bases disponíveis na UFPR são: Business Source Complete, Historical Abstracts with Full Text, Academic Search Premier, CINAHL with Full Text, Computers \& Applied Sciences Complete, Dentistry \& Oral Sciences Source, eBook Collection (EBSCOhost), Educational Administration Abstracts, Human Resources Abstracts, Information Science \& Technology Abstracts (ISTA), Library, Information Science \& Technology Abstracts with Full Text, MEDLINE Complete, Public Administration Abstracts, Regional Business News, RILM Abstracts of Music Literature (1967 to Present only), RIPM - Retrospective Index to Music Periodicals, SocINDEX with Full Text, SPORTDiscus with Full Text, MathSciNet via EBSCOhost, FSTA - Food Science and Technology Abstracts, American Doctoral Dissertations, 1933 - 1955 (UFPR, 2016).

Apesar da busca ter sido feita em todas as bases, as bases de Sociais Aplicadas relativas ao tema inovação são: Business Source Complete ${ }^{6}$, Academic Search Premier, Information Science \& Technology Abstracts (ISTA), Library, Information Science \& Technology Abstracts with Full Text, Public Administration Abstracts e SocINDEX with Full Text.

\subsection{A Relevância do Portal Scielo}

A rede Scientific Electronic Library Online (SciELO) é uma biblioteca eletrônica lançada há 17 anos que abrange uma coleção selecionada de periódicos científicos e constitui-se como resultado de um programa de acesso aberto de cooperação internacional em comunicação acadêmica. É uma rede de acesso gratuito, de cobertura multidisciplinar e de abrangência multinacional, permitindo a realização da busca integrada de artigos dos periódicos que, em 2013, cobria 16 países ibero-americanos mais a África do Sul (cada um deles publicando uma coleção de periódicos nacionais na rede) dentre eles: Argentina, Brasil, Chile, Colômbia, Cuba, Espanha, Portugal e Venezuela. Cada país participante gerencia uma coleção de acesso aberto online de periódicos avaliados pelos pares, denominada coleção nacional SciELO. Há também duas coleções temáticas: uma coleção temática internacional em saúde pública e uma coleção de ciências sociais da América Latina de artigos selecionados e traduzidos para o inglês (SCIELO, 2014, p. 41).

A rede é o resultado de um projeto de pesquisa da Fundação de Amparo à Pesquisa do Estado de São Paulo (FAPESP), que proporciona apoio político e financeiro para o desenvolvimento da coleção do SciELO Brasil, em parceria com o Centro Latino-Americano e do Caribe de Informação em Ciências da Saúde (BIREME) e que atende as estratégias de acesso aberto (AA) definidas pela UNESCO (SCIELO,

de bibliotecários que atuam como help-desks para prestar informações sobre o uso do Portal de Periódicos e o acesso às bases de dados e aos recursos de pesquisa que ele oferece (Brasil, 2015,d).

5 Esse grupo está listado como uma das 200 maiores empresas privadas dos Estados Unidos, emprega mais de 6.000 pessoas e está sediado em Birmingham, Alabama (COMPANY, 2016).

6 Base de dados de negócios que fornece o acesso a 5.347 revistas e jornais indexados, dos quais 3020 são revisados por pares ou especialistas. Destes periódicos, aproximadamente 3.820 publicações oferecem o texto completo, dentre estes são 1.982 os revisados (BUSINESS SourceComplete, 2016). A variada coleção de títulos contida no Business Source fornece informações que remontam a 1985. (UFPR, 2016). 
2014). Desde 2002, o Projeto conta com o apoio do Conselho Nacional de Desenvolvimento Científico e Tecnológico (CNPq) brasileiro. Com mais de um milhão e meio de downloads por dia, a rede conta com 950 periódicos e perto de 500 mil artigos disponíveis gratuitamente (SCIELO, 2014, p. 14-15).

Trata-se de fonte de Informação Científica e Tecnológica de importante expressão no contexto do acesso aberto. Dentre os repositórios digitais listados no Web Ranking Repositories, que avalia o impacto da produção científica de acesso aberto, o SciELO Brasil estava na primeira posição em 2013 (SCIELO, 2014, p. 15). A rede é também a maior provedora de periódicos indexados pelo Diretório de Periódicos de Acesso Aberto Directory of Open Access Journals (DOAJ). Importante ressaltar que nenhuma outra região no mundo tem esse nível de adoção de periódicos de acesso aberto indexados internacionalmente.

Este cenário de amplo acesso e uso de fontes de informação abertas reflete a importância do acesso aberto à viabilidade de publicações científicas produzidas dentro das próprias instituições públicas, por meio do compartilhamento destes recursos enquanto disseminadores da comunicação científica. O desenvolvimento destas coleções de ativos científicos proporciona a oferta de serviços de informação de uma forma sustentável além de um baixo custo.

\subsection{O Procedimento da Pesquisa}

A Estratégia de busca aplicada aos Portais foi estruturada da seguinte forma:

O descritor utilizado foi Inovação, junto com o recurso especial asterisco (*), como uma funcionalidade de truncagem, ou seja, recuperar um ou mais caracteres a partir da posição em que se encontra o $\left(^{*}\right)$.

Busca: Busca por inova* (em qualquer campo alvo de busca: Titulo, Autor,

Assunto, Resumo, Texto completo).

$\mathrm{O}(*)$ traz todos os derivados do termo inovação: inovatividade, inovar, inovações, inovador(a), etc.. Sem uso de qualquer operador booleano.

\begin{tabular}{ll}
\hline Periodicidade: & 5 em 5 anos (a partir de 01/01/1961 a 31/12/1965). \\
\hline Idioma: & Português.
\end{tabular}

Tipo do recurso ou Primeira busca feita por dissertações/teses e

fontes: $\quad$ Segunda busca por “artigos” (Capes), "revistas acadêmicas” (Ebscohost) e o Scielo só disponibiliza artigo.

Refinamento dos Por palavras chaves relacionadas aos estudos sobre inovação.

resultados:

Observação:

Conforme será visto nos diversos levantamentos feitos, estas bases fornecem dados diferentes, o que gera elevada incerteza quanto à confiabilidade. Supostamente as mesmas dissertações/teses/artigos deveriam ser encontradas em todas elas. A produção encontrada em uma base não aparece na outra (vice-versa).

\subsection{A Produção de Dissertações/teses sobre Innovation Studies}

A partir das diversas buscas nos portais, conforme QUADRO 4, foi possível encontrar dissertações/teses abordando Estudos de Inovação, no Brasil, a partir da segunda metade dos anos 60, com dois trabalhos defendidos entre 1966 e 1970. Conforme se nota neste quadro até os anos 90 foram produzidas algumas dissertações/teses esporádicas sobre o tema inovação que pela raridade podem ser mencionadas uma a uma. Porém, é apenas no início dos anos 90 (conforme a seguir) que se tem efetivamente um crescimento sistemático da produção sobre o tema propriamente. Também de acordo com o QUADRO 4 percebe-se a Unicamp como forte precursora das pesquisas nesta área. Por último, conforme a observação anterior, as dissertações/teses encontradas em uma base não apareceram na outra.

QUADRO 4 - DETALHES SOBRE AS PRIMEIRAS DISSERTAÇÕES/TESES DEFENDIDAS NO BRASIL SOBRE O TEMA INOVAÇÃO

\begin{tabular}{|c|c|c|c|c|c|}
\hline Ano & Autor & Título da Dissertação/Tese & Orientador & $\begin{array}{l}\text { Universidade/ } \\
\text { Departamento }\end{array}$ & Base \\
\hline \multirow{2}{*}{$\begin{array}{l}1966 \\
\text { A } \\
1970 \\
(2)\end{array}$} & $\begin{array}{l}\text { Molina } \quad \text { Filho, } \\
\text { José }\end{array}$ & $\begin{array}{l}\text { Adoção de inovações tecnológicas na } \\
\text { agricultura: aspectos teóricos e práticos. }\end{array}$ & ND & $\begin{array}{l}\text { USP/ } \\
\text { ESALQ }\end{array}$ & Ebscohost \\
\hline & \begin{tabular}{|l|} 
Schneider, João \\
Elmo
\end{tabular} & $\begin{array}{l}\text { A influência de fatores socioculturais na } \\
\text { inovabilidade e eficiência dos agricultores: } \\
\text { Estrela e Frederico Westphalen, RS. }\end{array}$ & $\begin{array}{l}\text { Alzemiro } \\
\text { Sturm }\end{array}$ & UFRGS & Ebscohost \\
\hline
\end{tabular}




\begin{tabular}{|c|c|c|c|c|c|}
\hline \multirow{4}{*}{$\begin{array}{l}1976 \\
\text { A } \\
1980 \\
(4)\end{array}$} & $\begin{array}{ll}\text { Souza, José } \\
\text { Henrique }\end{array}$ & $\begin{array}{l}\text { Os núcleos de articulação com a indústria: um } \\
\text { instrumento de política tecnológica para o } \\
\text { setor de bens de capital }\end{array}$ & $\begin{array}{l}\text { André } \\
\text { Furtado }\end{array}$ & $\begin{array}{l}\text { i UNICAMP/ } \\
\text { IG }\end{array}$ & Capes \\
\hline & \begin{tabular}{|l} 
Marion Mussoi, \\
Eros
\end{tabular} & $\begin{array}{l}\text { Importância de características individuais, } \\
\text { estruturais e de comunicação, associadas ao } \\
\text { grau de adoção de inovações em agricultura - } \\
\text { zona do meio oeste catarinense. }\end{array}$ & ND & $\begin{array}{l}\text { UFSM/ } \\
\text { Educação } \\
\text { Agrícola } \\
\text { Extensão Rural }\end{array}$ & $\mathrm{e}^{\text {Ebscohost }}$ \\
\hline & $\begin{array}{|ll|}\text { Tirone, } & \text { Luís } \\
\text { Fernando } & \\
\end{array}$ & $\begin{array}{l}\text { Política econômica e er desenvolvimento } \\
\text { tecnológico: diversificação ou especialização } \\
\text { no setor de bens de capital sob encomenda. }\end{array}$ & $\begin{array}{l}\text { Luciano Galvão } \\
\text { Coutinho }\end{array}$ & $\begin{array}{l}\text { UNICAMP/ } \\
\text { IE }\end{array}$ & Capes \\
\hline & $\begin{array}{|ll|}\text { Borges } & \text { da } \\
\text { Fonseca, } & \\
\text { Wellington } & \\
\end{array}$ & $\begin{array}{l}\text { Comunicação de massa e líderes de opinião no } \\
\text { processo de adoção de inovações em Viçosa } \\
\text { (MG). }\end{array}$ & $\begin{array}{l}\text { Francisco } \\
\text { Machado Filho }\end{array}$ & UFV & Ebscohost \\
\hline \begin{tabular}{|l|}
1981 \\
A \\
$1985(1)$ \\
\end{tabular} & \begin{tabular}{|l} 
Iazlovitch \\
Besnosik, \\
Roberto \\
\end{tabular} & $\begin{array}{l}\text { Modernização da agricultura e demanda de } \\
\text { energia. }\end{array}$ & $\begin{array}{l}\text { Antonio Barros de } \\
\text { Castro }\end{array}$ & $\begin{array}{l}\text { UFRJ/ } \\
\text { IEI }\end{array}$ & Ebscohost \\
\hline \multirow{7}{*}{$\begin{array}{l}1986 \\
\text { A } \\
1990 \\
(7)\end{array}$} & Baiardi, Amílcar & $\begin{array}{l}\text { Inovação tecnológica e trabalho assalariado na } \\
\text { agricultura brasileira: com estudos sobre as } \\
\text { lavouras de arroz, cana e cacau. }\end{array}$ & $\begin{array}{lr}\text { Tamas } & \text { Jozsef } \\
\text { Marton } & \text { Karoly } \\
\text { Szmrecsanyi }\end{array}$ & \multirow{3}{*}{$\begin{array}{l}\text { UNICAMP/ } \\
\text { IE }\end{array}$} & \multirow[b]{2}{*}{ Capes } \\
\hline & $\begin{array}{l}\text { Baptista, } \\
\text { Margarida } \\
\text { Afonso Costa }\end{array}$ & $\begin{array}{l}\text { A indústria eletrônica de consumo a nível } \\
\text { internacional e no Brasil: padrões de } \\
\text { concorrência, inovação tecnológica e caráter } \\
\text { da intervenção do Estado. }\end{array}$ & $\begin{array}{l}\text { no Galvão } \\
\text { hho }\end{array}$ & & \\
\hline & $\begin{array}{l}\text { Motta, } \\
\text { José }\end{array}$ & $\begin{array}{l}\text { Crise e inovação tecnológica: a visão das } \\
\text { correntes das ondas longas e da Escola } \\
\text { Francesa da Regulação }\end{array}$ & $\begin{array}{l}\text { Mario } \\
\text { Possas }\end{array}$ & & Capes \\
\hline & $\begin{array}{l}\text { Fleischfresser, } \\
\text { Vanessa }\end{array}$ & $\begin{array}{l}\text { Modernização tecnológica da agricultura: } \\
\text { contrastes regionais e diferenciação social no } \\
\text { Paraná da década de } 70\end{array}$ & $\begin{array}{l}\text { Nelson Giordano } \\
\text { Delgado }\end{array}$ & CPDA/UFRRJ & Ebscohost \\
\hline & $\begin{array}{l}\text { Porcile } \\
\text { Meirelles, } \\
\text { Gabriel }\end{array}$ & $\begin{array}{l}\text { Tecnologia, transformação industrial } \text { e } \\
\text { comércio internacional: uma revisão das } \\
\text { contribuições neo-schumpeterianas r rom } \\
\text { particular referencia as economias da América } \\
\text { Latina. }\end{array}$ & ND & UNICAMP/IE & Ebscohost \\
\hline & $\begin{array}{l}\text { Tucunduva, } \\
\text { Álvaro }\end{array}$ & $\begin{array}{l}\text { Geração de tecnologia para a pequena } \\
\text { propriedade rural: uma discussão conceitual e } \\
\text { apresentação de um estudo de caso para a área } \\
\text { de conservação de alimentos. }\end{array}$ & $\begin{array}{l}\text { Gregori Kil } \\
\text { Park }\end{array}$ & $\begin{array}{l}\text { UNICAMP/ } \\
\text { Faculdade } \\
\text { Engenharia } \\
\text { Agrícola } \\
\end{array}$ & Capes \\
\hline & $\begin{array}{|ll|}\text { De } & \text { Sousa, } \\
\text { Wilson } & \\
\text { Trigueiro } & \\
\end{array}$ & $\begin{array}{l}\text { Demanda dos principais metais e novos } \\
\text { materiais: análise de tendências. }\end{array}$ & $\begin{array}{ll}\text { Saul } & \text { Barisnik } \\
\text { Suslick } & \end{array}$ & $\begin{array}{l}\text { UNICAMP/ } \\
\text { Instituto } \\
\text { Geociências }\end{array}$ & Capes \\
\hline
\end{tabular}

FONTE: Elaboração própria com dados coletados em www.periodicos.capes.gov.br e https://www.ebscohost.com/

Numa visão de conjunto da evolução dos Estudos sobre Inovação em língua portuguesa as dissertações/teses tiveram um comportamento de mesma tendência ocorrido nas publicações (em revistas) em língua inglesa conforme relatado acima nos estudos de Fagerberg et al. (2012). Obviamente, o período de observação é bem menor uma vez que, eles se iniciaram de forma mais sistemática na década de 1990. Nesse período se inicia a consolidação dos Estudos sobre Inovação em língua portuguesa, a partir do que o crescimento se torna exponencial com queda importante no período 2011-2015, nas duas bases. Nas bases Capes e Ebscohost ${ }^{7}$ nota-se a evolução mais forte a partir da segunda metade da década de 1990. Na base Capes (GRÁFICO 5) percebe-se que praticamente todas as dissertações/teses que se referem a inovação são basicamente referentes aos Estudos sobre Inovação. Na base Ebscohost (GRÁFICO 6) há grande discrepância entre o total e as dissertações/teses sobre innovation studies, ou seja, há muitas dissertações sobre inovação, mas que não se referem a Estudos sobre Inovação, mas permanece a mesma tendência de grande crescimento de pesquisas sobre o tema.

${ }^{7}$ O GRÁFICO 5 e GRÁFICO 6 foram postos em separados por conta das quantidades que diferem de forma muito significativa nas duas bases, o que gera distorções no desenho das linhas do gráfico. 
GRÁFICO 5 - EVOLUÇÃO DO NÚMERO DE TESES/DISSERTAÇÕES SOBRE INNOVATION STUDIES E TOTAL SOBRE INOVAÇÃO EM GERAL DE TODAS AS ÁREAS DEFENDIDAS EM PORTUGUÊS - 1966-2015 - BASE CAPES

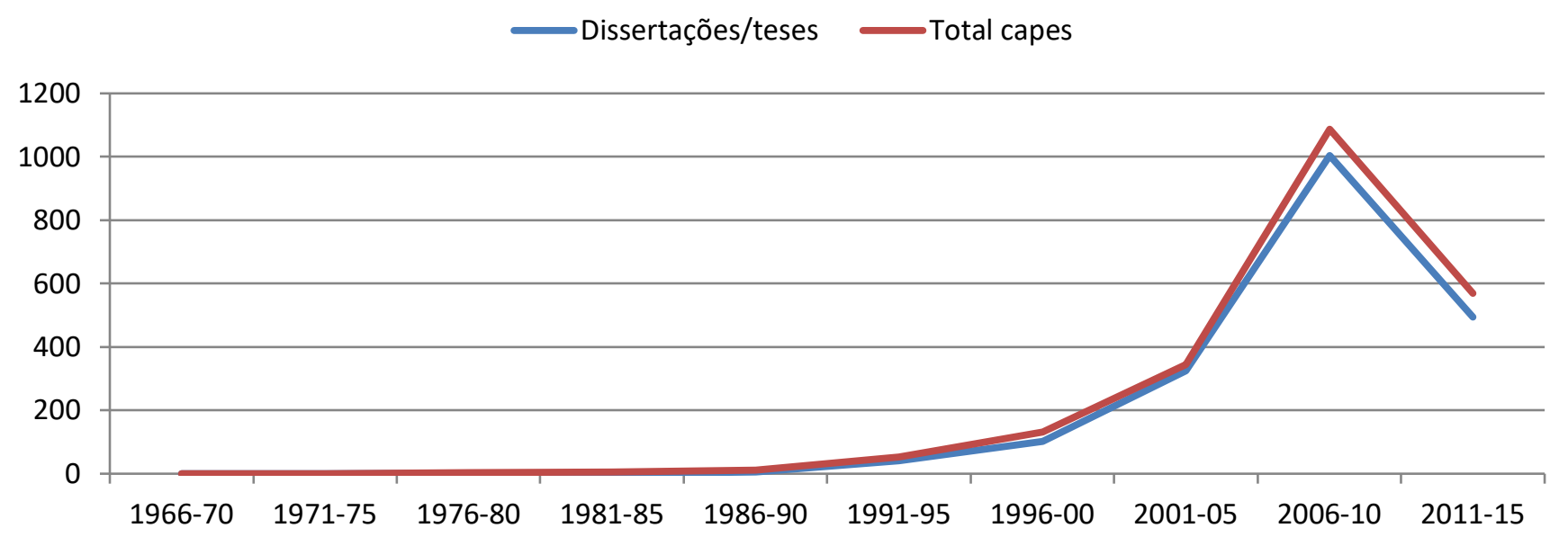

FONTE: Elaboração própria com dados coletados em www.periodicos.capes.gov.br

GRÁFICO 6 - EVOLUÇÃO DO NÚMERO DE TESES/DISSERTAÇÕES SOBREINNOVATION STUDIES E TOTAL SOBRE INOVAÇÃO EM GERAL DE TODAS AS ÁREAS DEFENDIDAS EM PORTUGUÊS - 1966-2015 - BASE EBSCOHOST

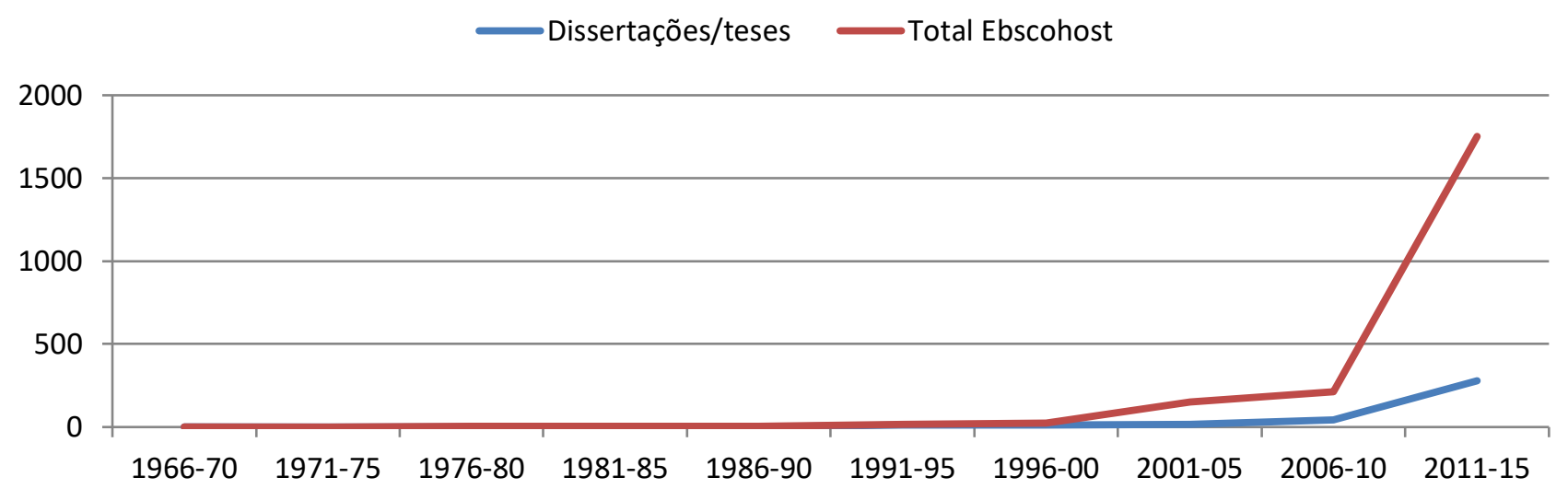

FONTE: Elaboração própria com dados coletados em https://www.ebscohost.com/

De toda essa produção acadêmica, quase que exclusivamente concentrada na Unicamp, no QUADRO 5, de acordo com a base Capes $^{8}$ estão os top 21 professores que mais orientaram dissertações/teses e/ou mais participaram de bancas de defesa sobre innovation studies durante o período 1976-2015. Dentro os 10 primeiros todos absolutamente da Unicamp, apenas o professor Guilherme Ary Plonski que é da USP consta, no período 2001-2005, como originário da Unicamp. Dessa forma, novamente a Unicamp confirma-se como precursora dos estudos no tema em língua portuguesa.

QUADRO 5 - TOP 21 PROFESSORES QUE MAIS ORIENTARAM E/OU PARTICIPARAM DE BANCAS - 1976-2015 BASE CAPES

\begin{tabular}{|l|l|l|l|}
\hline \multicolumn{1}{|c|}{$\mathbf{N}^{\mathbf{o}}$} & \multicolumn{1}{|c|}{$\begin{array}{c}\text { Professores que mais orientaram e/ou } \\
\text { participaram de bancas }\end{array}$} & $\begin{array}{c}\text { Numero de orientações e/ou } \\
\text { bancas }\end{array}$ & \multicolumn{1}{|c|}{ Universidade de origem } \\
\hline 1 & André Tosi Furtado & 35 & Unicamp \\
\hline 2 & Sergio Luiz Monteiro Salles Filho & 27 & Unicamp \\
\hline 3 & Ruy de Quadros Carvalho & 19 & Unicamp \\
\hline 5 & Sergio Robles Reis de Queiroz & 19 & Unicamp \\
\hline 5 & Leda Maria CairaGitahy & 18 & Unicamp \\
\hline
\end{tabular}

\footnotetext{
${ }^{8}$ A base Ebscohost não fornece esse nível de detalhamento de dados.
} 


\begin{tabular}{|l|l|l|l|}
\hline 6 & Maria Beatriz Machado Bonacelli & 17 & Unicamp \\
\hline 7 & Wilson Suzigan & 16 & Unicamp \\
\hline 8 & Antonio Batocchio & 14 & Unicamp \\
\hline 9 & Newton Muller Pereira & 11 & Unicamp \\
\hline 10 & Plonski, Guilherme Ary & 10 & USP/Unicamp \\
\hline 11 & Jose Maria Ferreira Jardim da Silveira & 9 & Unicamp \\
\hline 12 & Ademir Jose Petenate & 8 & Unicamp \\
\hline 13 & Amaral, Daniel Capaldo & 8 & USP \\
\hline 14 & Porto, Geciâne Silveira & 8 & USP \\
\hline 15 & Renato Peixoto Dagnino & 7 & Unicamp \\
\hline 16 & Sandra de Negraes Brisolla & 7 & Unicamp \\
\hline 17 & Lea Maria Leme Strini Velho & 6 & Unicamp \\
\hline 18 & Zouain, DesiréeMoraes & 6 & USP \\
\hline 19 & João Eduardo de Morais Pinto Furtado & 5 & Unicamp \\
\hline 20 & Oswaldo Luiz Agostinho & 5 & Unicamp \\
\hline 21 & Santos, Silvio Aparecido dos & 5 & USP \\
\hline
\end{tabular}

FONTE: Elaboração própria com dados coletados em www.periodicos.capes.gov.br

Apesar do mestrado em economia no IE/UNICAMP ter se iniciado em $1974^{9}$, já tendo uma bagagem em pós-graduação (latto sensu) desde 1968 e o doutorado ter se iniciado em 1977 é duvidoso, como se nota, que no Portal de Periódicos CAPES/MEC as buscas mostrem que a produção acadêmica tenha se concentrado quase que exclusivamente na Unicamp desde seu inicio. É como se os Estudos sobre Inovação fosse um tema exclusivo dela. Isso porque nesse tema outra instituição reconhecida é o Instituto de Economia da Universidade Federal do Rio de Janeiro (IE/UFRJ). A pesquisa neste instituto somente se inicia com o surgimento da pós-graduação, em 1978, quando se criou o Programa de Economia Industrial e da Tecnologia. Tratou-se da conjunção de um grupo de professores da Coppe/Produção (originários do Programa de Pós-graduação lá instalado denominado de Ecotec - Economia da Tecnologia), novos professores recém-iniciados e professores de economia como mais tempo de casa. Do lado da Coppe/UFRJ tratava-se de um grupo de engenheiros, com forte abordagem marxista, interessados na discussão sobre processos de trabalho, mudanças na organização da produção e toda a discussão que já nos anos 90, dentro do atual IE/UFRJ (no início da pós-graduação era IEI - Instituto de Economia Industrial), consolidar-se-ia como a ampla discussão do contraponto entre fordismo e as formas de automação flexível. O Professor José Ricardo Tauile de forte abordagem marxista, de fato, tornou-se a forte referencia do Instituto sobre esse tema (Kupfer, 2014).

Desse modo, portanto, o IE/UFRJ, ao longo do tempo, sempre se caracterizou por um forte enfoque em economia industrial e da tecnologia em que Steindl (1952)foi uma das bases teóricas precursoras. A obra de Steindl de 1952 analisa o padrão de concorrência do oligopólio tendo como pressuposto o investimento em capacidade ociosa da indústria para (1) responder rapidamente ao crescimento da demanda e assim (2) impedir a entrada e acompanhar o seu crescimento paulatino ao longo do tempo (da demanda). Um terceiro fator que levava ao crescimento da capacidade ociosa era a indivisibilidade técnica das plantas. Ou seja, as plantas tecnicamente nunca eram construídas exatamente de acordo com o tamanho ou o requerimento do produtor. Essa capacidade ociosa funcionava como forte barreira à entrada e no longo prazo levaria a uma inibição dos investimentos e dada o potencial de acumulação interna das firmas progressistas haveria sempre um processo de concentração relativa ou absoluta da indústria. Steindl não estava explicitamente preocupado com inovação e tecnologia. $\mathrm{O}$ pressuposto dele era de que o investimento era exclusivamente feito dentro da própria indústria e toda tecnologia também era apenas redutora de custo (ou seja, levava em consideração apenas as inovações de

\footnotetext{
${ }^{9}$ Outro departamento importante em Estudos sobre Inovação na Unicamp é o Departamento de Políticas Científicas e Tecnológicas. Entretanto, sua história é bem mais recente. Teve inicio com o mestrado em 1988 e o doutorado em 1995. Portanto, sua produção inicial não aparece ainda entre os primeiros em língua portuguesa.
} 
processo). Essa abordagem é o que teria fundamentado um dos primeiros grandes estudos sobre indústria no Brasil financiado pela FINEP e coordenado pela Professora Maria da Conceição Tavares intitulado Estrutura Industrial e Empresas Lideres, em 1978. Não somente essa abordagem é importante na consolidação do IEI/UFRJ, mas também a forte inspiração keynesiana/kaleckiana herdada do IE/UNICAMP. Mais no início dos anos 90 na linha da indústria/inovação reforça-se no IE/UFRJ os Estudos sobre Inovação com a oferta de uma disciplina sobre Economia Neo-Schumpeteriana na pósgraduação, a partir da transferência do Professor Mario Luiz Possas do IE/UNICAMP, apesar de já estarem ativos na mesma linha de pesquisa os professores precursores do tema Fábio Stefano Erber, Eduardo Augusto de Almeida Guimarães, José Tavares de Araújo Junior, Antonio Barros de Castro e Paulo Bastos Tigre. Ou seja, ao longo do tempo se reforça nesse centro a relevância dos Estudos sobre Inovação.

Na verdade o ambiente no em torno da criação doIE/UNICAMP eIEI/UFRJ é fortemente marcado pela discussão de origem cepalina de superação do subdesenvolvimento que somente dar-se-ia pela industrialização. A deterioração dos termos de troca ao longo dos anos foi percebida por Prebisch e que isto estaria impondo às economias latino-americanas uma perda importante no comércio internacional. Ele e os demais economistas brasileiros (Celso Furtado, Maria da Conceição Tavares, Carlos Lessa e Antônio Barros de Castro) estavam convencidos de que era necessário o esforço da industrialização mesmo que tardia para superar o atraso destas economias. Nisso as políticas industriais teriam papel de extrema relevância.

Tendo isso em conta, portanto, naquele momento dos anos 70 a preocupação com a inovação per se era indireta e estava implícita nas discussões sobre industrialização. Não havia no Brasil uma preocupação explicita com o tema. Como se nota acima, a produção em língua inglesa sobre o tema ainda está nos seus primeiros anos. A preocupação com a industrialização no Brasil em seus diversos momentos de política industrial (explicita ou não) trouxe resultados relevantes para o desenvolvimento, mas a inovação como elemento competitivo a la Schumpeter ainda não havia sido percebida como relevante. Isso também se explica pelo fato de que, também o paradigma técno-econômico vigente não colocava às políticas industriais a necessidade de se pensar inovação como carro-chefe das dinâmicas industriais.

A contribuição importante para o avanço dos Estudos sobre Inovação no IEI/UFRJ vem da Inglaterra. Há um conjunto de professores formados neste país, especificamente no SPRU/Sussex no seu inicio, responsáveis pelo direcionamento da instituição para os Estudos sobre Inovação e indústria. Conforme o QUADRO 6 dos 7 professores iniciais do IEI doutorado na Inglaterra, 5 obtiveram o título no SPRU/Sussex. Conforme também se nota, todas as teses versaram sobre inovação/indústria. Apenas Helena Maria Martins Lastres e Jose Eduardo Cassiolato obtiveram o doutorado mais recentemente, mas ainda num tempo de consolidação da pós-graduação, quando, por exemplo, o doutorado iniciado em 1988, ainda tinha nenhuma teses defendida. A primeira tese de doutorado defendida no IE/UFRJ foi a de COSTA(1993), sobre a Modernização e Competitividade da Indústria de Calçados Brasileira, orientada por Paulo Bastos Tigre que trata amplamente da trajetória de inovação de processo e produto nessa indústria e que tem o termo inovação no Resumo, não apareceu em qualquer momento no Portal Capes/MEC.

QUADRO 6 - PROFESSORES DO IE/UFRJ PRECURSORES DOS ESTUDOS SOBRE INOVAÇÃO NO BRASIL

\begin{tabular}{|c|c|c|c|}
\hline Ano & Autor & Título da tese & Local de obtenção \\
\hline 1978 & Fábio Stefano Erber & $\begin{array}{l}\text { Technological Development and State Intervention: } \\
\text { A Study of The Brazilian Capital Goods Industry }\end{array}$ & $\begin{array}{l}\text { Universidade de Sussex, } \\
\text { Inglaterra. }\end{array}$ \\
\hline 1980 & $\begin{array}{l}\text { Eduardo Augusto } \\
\text { Almeida Guimarães }\end{array}$ & $\begin{array}{l}\text { Industry, Market Structure and the Growth of the } \\
\text { Firm in the Brazilian Economy }\end{array}$ & $\begin{array}{l}\text { Universidade de } \\
\text { University College. }\end{array}$ \\
\hline 1982 & $\begin{array}{l}\text { José Tavares de Araújo } \\
\text { Junior }\end{array}$ & $\begin{array}{l}\text { Technical Progress and Forms of Competition, A } \\
\text { Case Study of the Glass Industry }\end{array}$ & $\begin{array}{l}\text { Universidade de } \\
\text { University College. }\end{array}$ \\
\hline 1982 & Paulo Bastos Tigre & $\begin{array}{l}\text { Technology and Competition in the Brazilian } \\
\text { Computer Industry }\end{array}$ & $\begin{array}{l}\text { Universidade de } \\
\text { Inglaterra. }\end{array}$ \\
\hline 1984 & João Carlos Ferraz & $\begin{array}{l}\text { Technological Development and Conditioning } \\
\text { Factors: the Case of the Brazilian Shipbuilding } \\
\text { Industry }\end{array}$ & $\begin{array}{l}\text { Universidade } \\
\text { Inglaterra. }\end{array}$ \\
\hline 1992 & Martins & Advanced Materials and the Japanese National & Universidade \\
\hline
\end{tabular}




\begin{tabular}{|l|l|l|lc|}
\hline & Lastres & System of Innovation & Inglaterra. & \\
\hline 1992 & Jose Eduardo Cassiolato & $\begin{array}{l}\text { The Role of User-Producer in Innovation and } \\
\text { Diffusion of New Technologies }\end{array}$ & $\begin{array}{l}\text { Universidade de Sussex, } \\
\text { Inglaterra. }\end{array}$ & \\
\hline
\end{tabular}

FONTE: Elaboração própria (2016).

\subsection{A Publicação em Revistas Científicas sobre Innovation Studies}

Conforme o QUADRO 7 a primeira publicação em revistas cientificas, como mecanismo de maior difusão dessa nova área de pesquisa em língua portuguesa, foi em 1975 em Portugal e somente em 1978 no Brasil. Também decorre desse mesmo QUADRO 7 que nenhum dos autores de artigos em revista cientifica é o das dissertações do QUADRO 4, o que demonstra, naquela época, a despreocupação com a divulgação dos resultados das pesquisas realizadas nas dissertações/teses. A pesquisa resgata dois artigos de João Tolda publicados em Portugal. Nas bases Capes, Ebscohost e Scielo, publicações portuguesas aparecem eventualmente na busca por artigos, porém, nunca aparecem dissertações/teses dessa mesma origem.

QUADRO 7 - OS PRIMEIROS ARTIGOS PUBLICADOS EM LÍNGUA PORTUGUESA EM REVISTAS CIENTIFICAS

\begin{tabular}{|c|c|c|c|c|}
\hline Ano & Autor & Titulo & Revista & Base \\
\hline 1975 & $\begin{array}{ll}\text { Cabral, } & \text { Manuel } \\
\text { Villaverde } & \end{array}$ & $\begin{array}{l}\text { Crescimento econômico e progresso } \\
\text { tecnológico: Pesquisa bibliográfica para servir à } \\
\text { sociologia histórica do desenvolvimento. }\end{array}$ & $\begin{array}{l}\text { Revista Análise Social, } \\
\text { 1/1/1975, Vol. 11, Issue 44, } \\
\text { p. 538-575. Portugal }\end{array}$ & Ebscohost \\
\hline 1978 & Claude Machline & $\begin{array}{l}\text { Inovação, gestão e decisão tecnológicas na } \\
\text { indústria alimentícia brasileira }\end{array}$ & $\begin{array}{l}\text { Revista de } \\
\begin{array}{l}\text { Empresas. } \\
\text { Eministração de } \\
\text { 18(3):57-82 }\end{array}\end{array}$ & $\begin{array}{l}\text { Ebscohost e } \\
\text { Scielo }\end{array}$ \\
\hline 1991 & $\begin{array}{l}\text { Silvio Roberto } \\
\text { Souza Tavares }\end{array}$ & $\begin{array}{l}\text { Modernização industrial em indústria de mão- } \\
\text { de-obra: automação, informatização e inovações } \\
\text { organizacionais na indústria do vestuário. }\end{array}$ & $\begin{array}{l}\text { Produção, Vol1, Iss 1, P. 41- } \\
48\end{array}$ & Capes \\
\hline 1992 & $\begin{array}{l}\text { Guilherme } \quad \text { Ary } \\
\text { Plonski }\end{array}$ & $\begin{array}{l}\text { Inovando métodos na educação continuada dos } \\
\text { engenheiros de produção. }\end{array}$ & $\begin{array}{l}\text { Produção, Vol. 2, Iss 1, P. } \\
71-80\end{array}$ & Capes \\
\hline 1994 & $\begin{array}{l}\text { Marcia } \quad \text { Regina } \\
\text { Gabardo da Câmara }\end{array}$ & $\begin{array}{l}\text { A inovação técnica em Mill e Marx e as raízes } \\
\text { do pensamento preservacionista contemporâneo. }\end{array}$ & $\begin{array}{l}\text { Semina : Ciências Sociais e } \\
\text { Humanas, Vol 15, Iss 3, P. } \\
217-222\end{array}$ & Capes \\
\hline 1994 & $\begin{array}{l}\text { H. Maria Dutilh } \\
\text { Novaes \& Ricardo } \\
\text { Lafetá Novaes }\end{array}$ & Saúde, doença e inovação tecnológica. & $\begin{array}{l}\text { Saúde e Sociedade, Vol3, Iss } \\
\text { 1, P. 61-78 }\end{array}$ & Capes \\
\hline 1995 & João Tolda & $\begin{array}{l}\text { Inovação Empresarial e Economia Regional da } \\
\text { Inovação: dados de uma investigação em curso. }\end{array}$ & $\begin{array}{l}\text { Revista Critica de Ciências } \\
\text { Sociais - } 44 \text { (Portugal) }\end{array}$ & Capes \\
\hline 1995 & João Tolda & $\begin{array}{l}\text { Investimentos Empresariais em Inovação e } \\
\text { Processos de Industrialização: a Construção de } \\
\text { uma Matriz de Análise. }\end{array}$ & $\begin{array}{llr}\text { Workingpaper } & \text { - Centro } & \text { de } \\
\text { Estudos } & \text { Sociais } & - \\
\text { Universidade de Coimbra } & \end{array}$ & Capes \\
\hline
\end{tabular}

FONTE: Elaboração própria com dados coletados em www.periodicos.capes.gov.br, https://www.ebscohost.com/ e http://www.scielo.org/php/index.php

Na sequencia, na TABELA 1 e nos GRÁFICO 7, GRÁFICO 8, GRÁFICO 9 e GRÁFICO 10 está a evolução do numero de artigos produzidos em português sobre innovation studies e o total (em português de outras áreas que se referem ao termo inovação de forma mais geral) nas bases Capes, Scielo e Ebscohost. Nota-se ai a grande expansão da produção em português, seguindo a mesma tendência e ritmo da produção total. Da mesma forma que anteriormente, os gráficos foram postos em separados por conta da absoluta discrepância entre as bases. Nota-se na TABELA 1 que a quantidade de artigos encontrada nas três bases difere absolutamente, por exemplo, enquanto no quinquênio 2011-15 na Capes houve 3.491 no total de artigos, na Ebscohost houve 17.562!!Ainda, na Capes os primeiros artigos somente aparecem no quinquênio 1991-95 enquanto na Ebscohost aparecem já em 1971-75 e na Scielo em 1976-80. Desde a perspectiva bibliotecária isso demonstra algum problema de catalogação ou de 
forma como os portais agregam as informações. Está foi uma questão não respondida pelos responsáveis pelo Portal Capes. Por outro lado, as três bases, conforme GRÁFICO 7, GRÁFICO 8 e GRÁFICO 9, confirmam que a grande expansão da produção de artigos ocorre somente a partir do quinquênio 2001-05. Por último, o GRÁFICO 10 mostra que a produção sobre innovation studies vem aumentando sua participação no total de produção sobre inovação em língua portuguesa. Ou seja, cada vez mais esse tema vem se tornando o estudo mais relevante comparativamente a estudos que tenham referencia a inovação em todas as demais áreas do conhecimento. Está havendo uma tendência a que a referencia a inovação em língua portuguesa basicamente se refira cada vez mais a Estudos sobre Inovação.

TABELA 1-QUANTIDADE DE ARTIGOS SOBRE INNOVATION STUDIES E TOTAL DE ARTIGOS COM REFERENCIA A INOVAÇÃO EM GERAL - 1971 A 2015 - BASE CAPES, SCIELO E EBSCOHOST

\begin{tabular}{|c|c|c|c|c|c|c|c|c|c|}
\hline Quinquênio & Capes & Total & $\%$ & Scielo & Total & $\%$ & Ebscohost & Total & $\%$ \\
\hline 1971-75 & 0 & 0 & 0 & 0 & 0 & 0 & 1 & 10 & $10,00 \%$ \\
\hline $1976-80$ & 0 & 0 & 0 & 1 & 2 & $50,00 \%$ & 1 & 49 & $2,04 \%$ \\
\hline $1981-85$ & 0 & 0 & 0 & 4 & 8 & $50,00 \%$ & 19 & 76 & $25,00 \%$ \\
\hline $1986-90$ & 0 & 0 & 0 & 2 & 6 & $33,33 \%$ & 16 & 82 & $19,51 \%$ \\
\hline 1991-95 & 6 & 17 & $35,29 \%$ & 13 & 27 & $48,15 \%$ & 38 & 147 & $25,85 \%$ \\
\hline 1996-00 & 97 & 245 & $39,59 \%$ & 31 & 104 & $29,81 \%$ & 146 & 566 & $25,80 \%$ \\
\hline 2001-05 & 357 & 666 & $53,60 \%$ & 65 & 254 & $25,59 \%$ & 448 & 1.706 & $26,26 \%$ \\
\hline 2006-10 & 1.027 & 2.109 & $48,70 \%$ & 234 & 629 & $37,20 \%$ & 2.671 & 10.658 & $25,06 \%$ \\
\hline 2011-15 & 1.706 & 3.491 & $48,87 \%$ & 276 & 1.109 & $24,89 \%$ & 4.755 & 17.562 & $27,08 \%$ \\
\hline
\end{tabular}

FONTE: Elaboração própria com dados coletados em www.periodicos.capes.gov.br, https://www.ebscohost.com/ e http://www.scielo.org/php/index.php

GRÁFICO 7 - EVOLUÇÃO DA PRODUCAO DE ARTIGOS SOBRE INNOVATION STUDIES E TOTAL - BASE CAPES

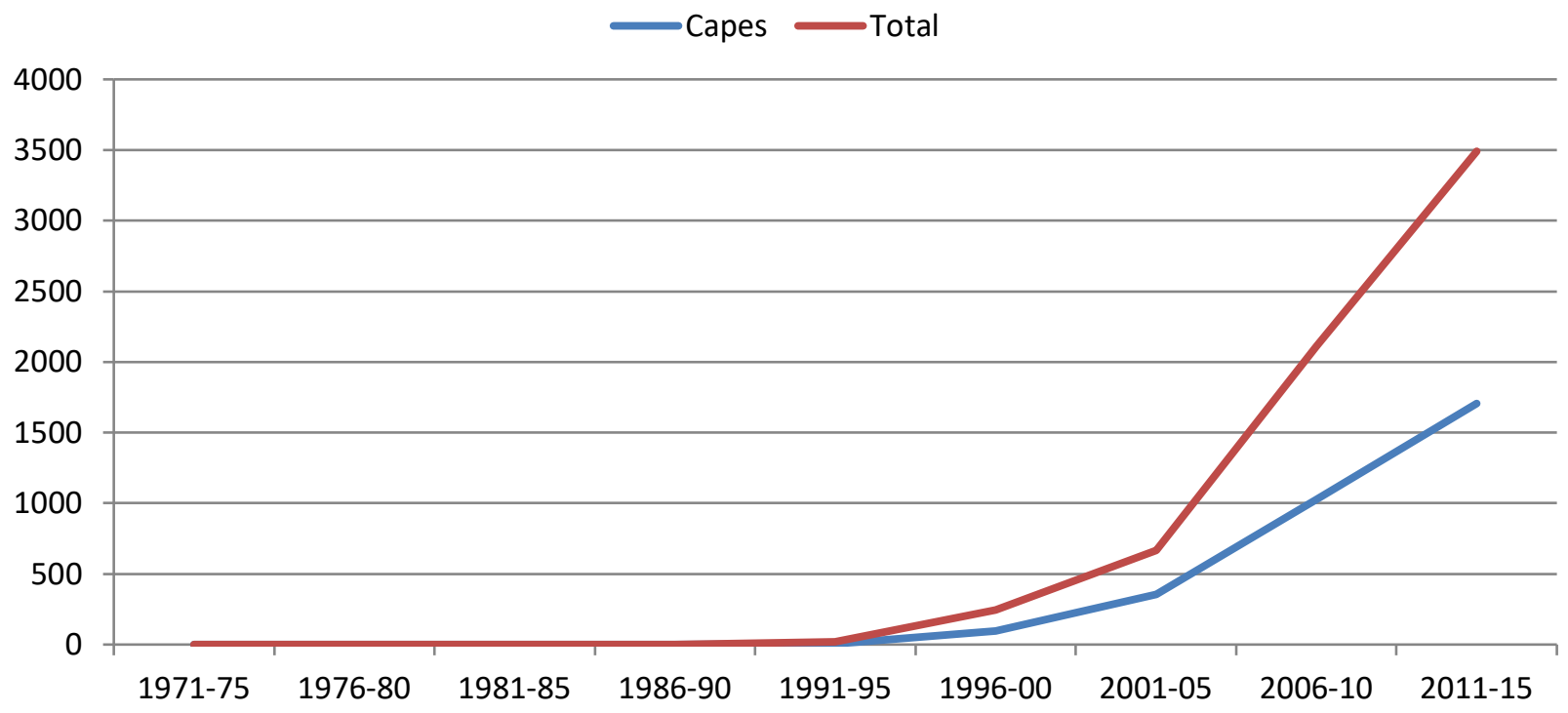

FONTE: Elaboração própria com dados coletados em www.periodicos.capes.gov.br

GRÁFICO 8 -EVOLUÇÃO DA PRODUCAO DE ARTIGOS SOBRE INNOVATION STUDIES E TOTAL - BASE SCIELO 


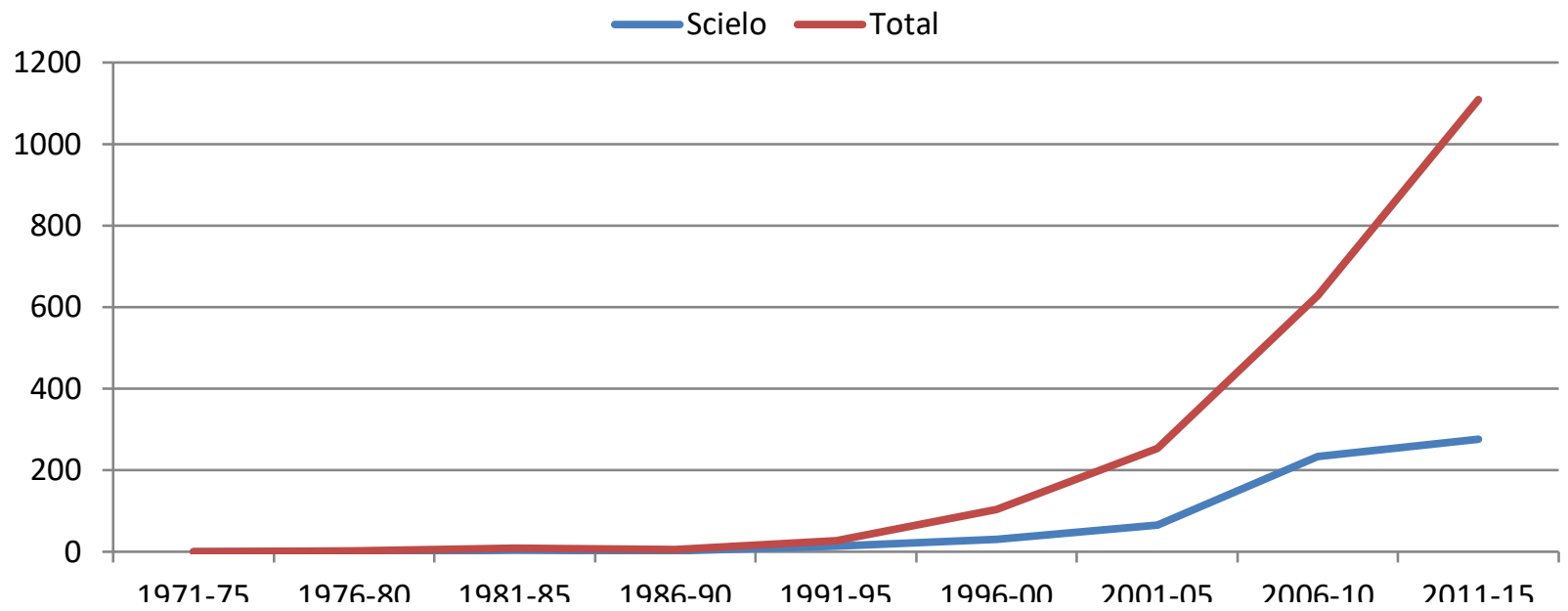

FONTE: elaboração própria com dados coletados em http://www.scielo.org/php/index.php

GRÁFICO 9 - EVOLUÇÃO DA PRODUCAO DE ARTIGOS SOBRE INNOVATION STUDIES E TOTAL - BASE EBSCOHOST

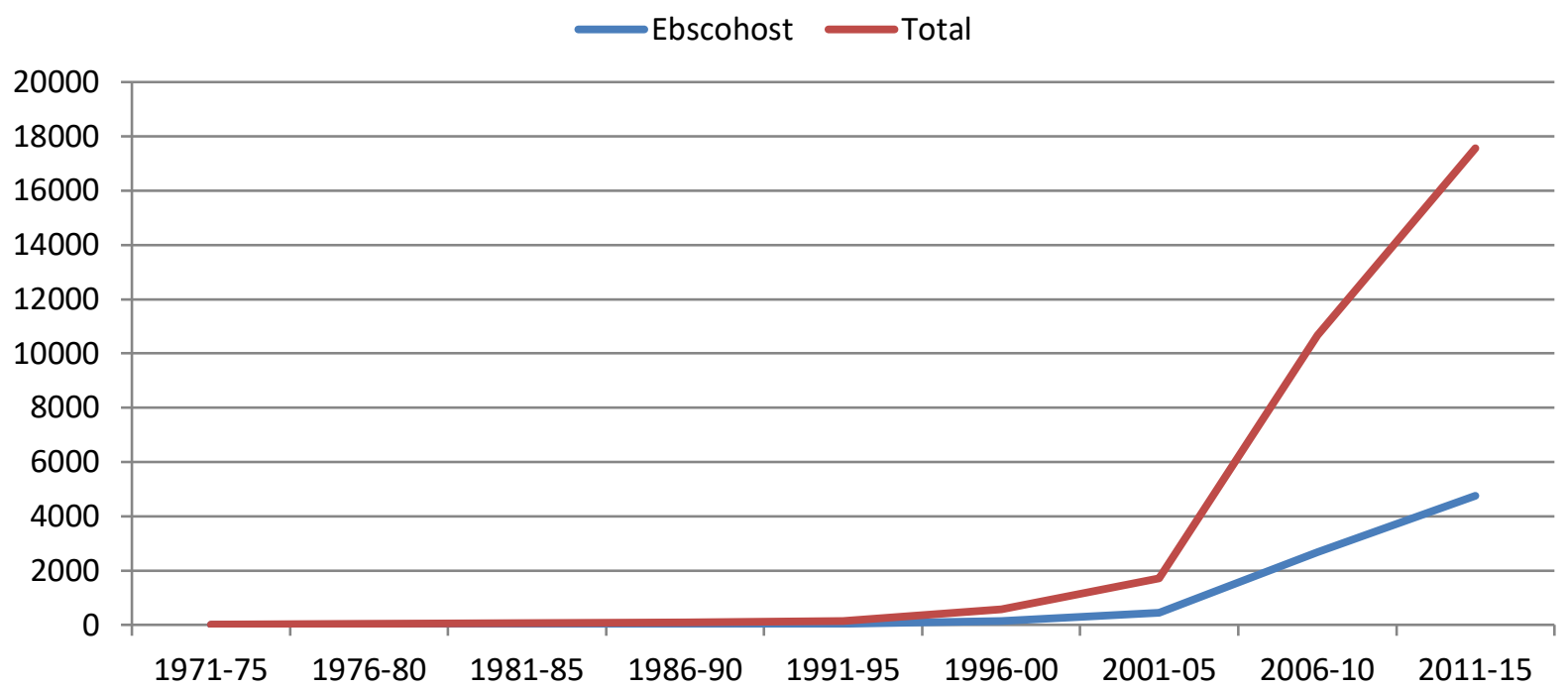

FONTE: Elaboração própria com dados coletados em https://www.ebscohost.com/

GRÁFICO 10 - EVOLUCAO DO \% DE ARTIGOS SOBRE INNOVATION STUDIES NO TOTAL DE ARTIGOS SOBRE INOVACAO EM GERAL

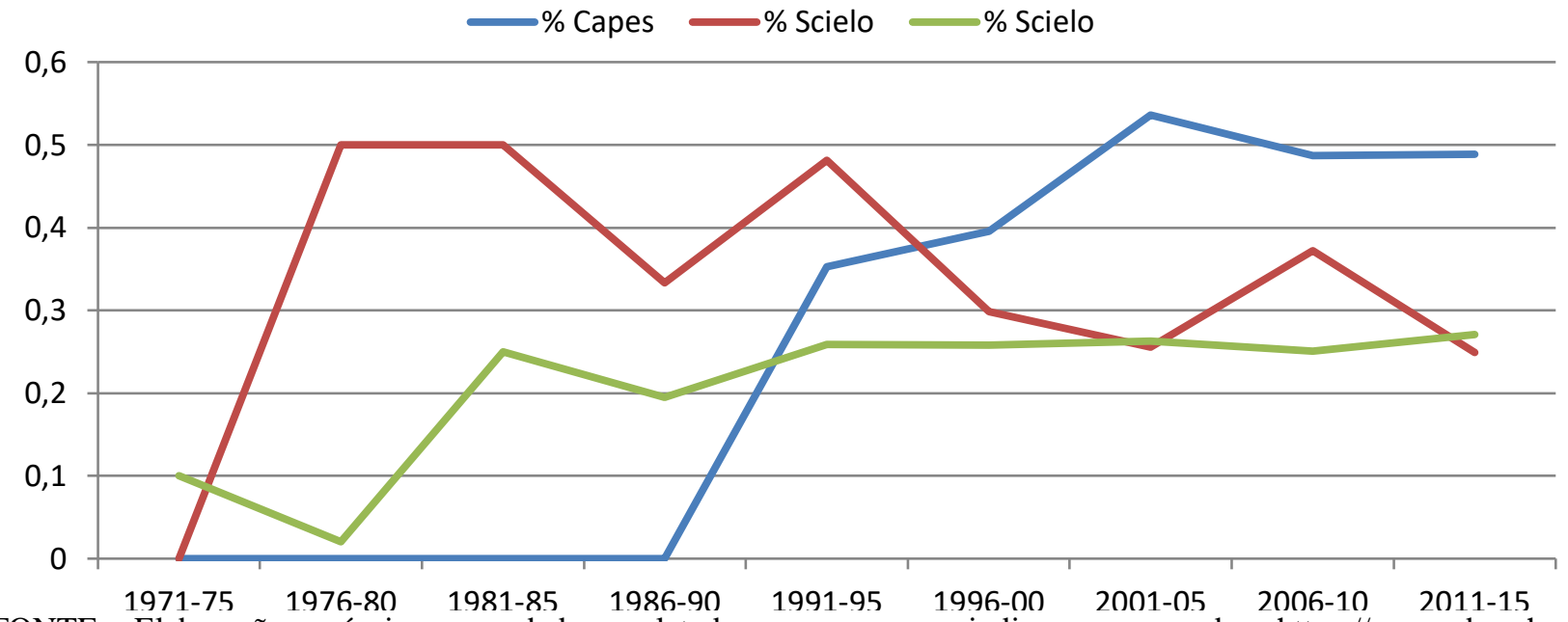

FONTE: Elaboração própria com dados coletados em www.periodicos.capes.gov.br, https://www.ebscohost.com/ e http://www.scielo.org/php/index.php 


\section{Conclusão}

Com base nos estudos de Fagerberg et al. (2012) o objetivo desse artigo foi de avaliar a evolução da relevância dos Estudos sobre Inovação em língua portuguesa. Na medida da disponibilidade dos dados foram feitos levantamentos semelhantes aos feitos nesse artigo, de forma a se ter uma análise comparativa de como tem evoluído essa produção. A pergunta inicial foi: qual é a relevância que os Estudos sobre Inovação assumiram nas publicações em língua portuguesa?

Para responder a essa pergunta foram feitas buscas Portal de Periódicos da Coordenação de Aperfeiçoamento de Pessoal de Nível Superior (CAPES), no serviço de informação Ebscohost e na biblioteca eletrônica SciELO que são as bases mais importantes e abrangentes de publicações entre outras línguas a portuguesa.

A estratégia de busca foi a de usar o descritor Inovação, junto com o recurso especial asterisco $(*)$, como uma funcionalidade de truncagem que recupera um ou mais caracteres a partir da posição em que se encontra o (*). Desse modo, a pesquisa traria todos os derivados do termo inovação: inovatividade, inovar, inovações, inovador(a), etc.. A busca foi feita em qualquer campo alvo de busca: Titulo, Autor, Assunto, Resumo, Texto completo; sem uso de qualquer operador booleano; com periodicidade de 5 em 5 anos (a partir de 01/01/1961 a 31/12/1965); idioma português.

A partir das diversas buscas nos portais foi possível encontrar dissertações/teses abordando Estudos de Inovação, no Brasil, a partir da segunda metade dos anos 60, com dois trabalhos defendidos entre 1966 e 1970. Até os anos 90 as dissertações/teses sobre esse tema eram esporádicas. Somente no início dos anos 90 é que se tem efetivamente um crescimento sistemático da produção sobre o tema propriamente. Para esse tipo de produção a indicação nas buscas feitas é que a Unicamp aparece como a forte precursora das pesquisas nesta área. Desse modo, nota-se que a evolução dos Estudos sobre Inovação em língua portuguesa nas dissertações/teses teve um comportamento de mesma tendência ocorrido nas publicações (em revistas) em língua inglesa conforme relatado acima nos estudos de Fagerberg et al. (2012).

Apesar dos dados mostrarem a Unicamp como precursora e mais importante instituição nas pesquisas sobre o tema é importante corrigir o fato de que o Instituto de Economia da Universidade Federal do Rio de Janeiro (IE/UFRJ) também é uma das instituições precursoras nos Estudos sobre Inovação a partir da criação da pós-graduação, em 1978, quando se criou o Programa de Economia Industrial e da Tecnologia. Trata-se de uma instituição que está na raiz da discussão acadêmica sobre industrialização no Brasil. Sempre houve um forte enfoque em economia industrial e da tecnologia em que Steindl foi uma das suas bases teóricas precursoras e que teria fundamentado um dos primeiros grandes estudos sobre indústria no Brasil financiado pela FINEP e coordenado pela Professora Maria da Conceição Tavares intitulado Estrutura Industrial e Empresas Lideres, em 1978. Portanto, naquele momento dos anos 70 a preocupação com a inovação per se era indireta e estava implícita nas discussões sobre industrialização. Não havia ainda no Brasil uma preocupação explicita com o tema ela ainda é um tema implícito da indústria. Como se percebeu, a produção em língua inglesa sobre o tema ainda está nos seus primeiros anos.

No que se refere a publicação em revistas cientificas, verificou-se que as primeiras publicações ocorreram em 1975 em Portugal e somente em 1978 no Brasil. Nota-se a partir dos anos 2000 a grande expansão da produção em português, seguindo a mesma tendência e ritmo da produção total. Do ponto de vista bibliométrico é importante atentar para o fato que a quantidade de artigos encontrada nas três bases difere absolutamente, por exemplo, enquanto no quinquênio 2011-15 na Capes houve 3.491 no total de artigos, na Ebscohost houve 17.562!! Desde a perspectiva bibliotecária isso demonstra algum problema de catalogação ou de forma como os portais agregam as informações. Está foi uma questão não respondida pelos responsáveis pelo Portal Capes. Ainda, na Capes os primeiros artigos somente aparecem no quinquênio 1991-95 enquanto na Ebscohost aparecem já em 1971-75 e na Scielo em 1976-80. Por último, verificou-se que a produção sobre innovation studies vem aumentando sua participação no total de produção sobre inovação em língua portuguesa.

Em síntese: a produção acadêmica em língua portuguesa, na medida da relevância deste idioma, seguiu a mesma tendência da produção em língua inglesa em termos relativos. Ou seja, houve muito mais produção acadêmica no sentido de dissertações/teses do que artigos em revistas científicas. A 
preocupação com esse tipo de publicação somente se inicia num momento - início dos anos 2000 - em que passa haver por parte da Capes uma regulação mais intensa dos programas de pós-graduação em termos de qualidade e produção cientifica. Trata-se de uma área do conhecimento complemente internalizada nos programas de pós-graduação nas áreas de ciências sociais aplicadas no Brasil que teve o desenvolvimento a partir da formação de parte de professores no SPRU/SUSSEX, mas que já se encontra totalmente autônoma no sentido de desenvolver esse tema dentro da realidade do desenvolvimento da inovação no país.

\section{Bibliografia}

BRASIL. Coordenação de Aperfeiçoamento de Pessoal de Nível Superior (Capes). Ministério da Educação (MEC). 2013a. Estatísticas de Uso: 2004-2013. Acesso em 27 abr. 2016. Disponível em: < http://goo.gl/2YFLCB>.

BRASIL. Coordenação de Aperfeiçoamento de Pessoal de Nível Superior (Capes). Ministério da Educação (MEC). 2008. História e missão. Acesso em 15 abr. 2016. Disponível em: <http://goo.gl/82H73k>.

BRASIL. Coordenação de Aperfeiçoamento de Pessoal de Nível Superior (Capes). Ministério da Educação (MEC). 2013b. Orçamentos: Dotação e Execução - PPA 2012-2013. Acesso em 27 abr. 2016. Disponível em: < http://goo.gl/MdK11Q>.

BRASIL. Coordenação de Aperfeiçoamento de Pessoal de Nível Superior (Capes). Ministério da Educação (MEC). 2015a. Portal de Periódicos Capes/MEC: Missão e Objetivos. Acesso em 15 abr. 2016. Disponível em: $<$ http://goo.gl/NgtBOf>.

BRASIL. Coordenação de Aperfeiçoamento de Pessoal de Nível Superior (Capes). Ministério da Educação (MEC). 2015b. Quem Participa: Instituições Participantes.. Acesso em 15 abr. 2016. Disponível em: $<\mathrm{http} / / /$ goo.gl/kC790R>.

BRASIL. Coordenação de Aperfeiçoamento de Pessoal de Nível Superior (Capes). Ministério da Educação (MEC). 2015c. Dispositivos móveis. Acesso em 15 abr. 2016. http://goo.gl/m0YpjO.

BRASIL. Coordenação de Aperfeiçoamento de Pessoal de Nível Superior (Capes). Ministério da Educação (MEC). 2015d. Help Desk. Acesso em 15 maio 2015. Disponível em: <http://goo.gl/wz8Lv3>.

COMPANY Profile: EBSCO Industries Inc. MarketLine, 2016. Disponível em: $<$ http://search.ebscohost.com/login.aspx?direct=true\&db=dmhls\&AN=3B25272D-D5F1-42EE-9C1594B3737AD75B\&lang=pt-br\&site=ehost-live>. Acesso em: 19 maio 2016. 24 p.

CORREA, Cynthia Harumi Watanabe; CRESPO, Isabel Merlo; STUMPF, Ida Regina Chitto; CAREGNATO, Sonia Elisa. Portal de Periódicos da CAPES: um misto de solução financeira e inovação. Revista Brasileira de Inovação, n. 1, p. 127-145, jan./jun. 2008. Disponível em: <http://goo.gl/Pqtn8d>. Acesso em 25 abr. 2016.

COSTA, Achyles Barcelos da. Modernização e Competitividade da Indústria de Calçados Brasileira. Tese (Doutorado) - Instituto de Economia, Universidade Federal do Rio de Janeiro, Rio de Janeiro, 1993.

DOSI, Giovanni. Technological Paradigms and Technological Trajectories: A suggested interpretation of the determinants and directions of technical change. Research Policy, v.11, p. 147-162, 1982.

FAGERBERG, Jan ; SAPPRASERT, Koson. National innovation systems: the emergence of a new approach. Science and Public Policy, v. 38, n. 9, Nov. 2011, p. 669-679.

FAGERBERG, Jan; FOSAASA, Morten; SAPPRASERTA, Koson. Innovation: Exploring the knowledge base. Research Policy, n. 41, 2012, p. 1132- 1153.

FREEMAN C. Technology Policy and Economic Performance: Lessons from Japan, 1987.

FREEMAN, C.; PEREZ, C. Structural crises of adjustment: business cycles and investment behavior. In: Dosi et al. Technical Change and Economic Theory. London: Pinter Publishers, 1988.

KUPFER, David. Instituto de Economia 75 anos : Palestra David Kupfer, Indústria de tecnologia. 22 ago. 2014. Disponível em: <https://www.youtube.com/watch?v=nDV5etHptD8>. Acesso em: 30 out. 2015.

LUNDVALL B-Å. National Innovation Systems: Towards a Theory of Innovation and Interactive Learning. 1992. 
PAVITT, K. Key characteristics of large innovating firms. In: DODGSON, M. ; ROTHWELL, R. The handbook of industrial innovation. Edward Elgar, 1994.

PAVITT, Keith. Sectoral Patterns of Technical Change: Towards a Theory and a Taxonomy. Research Policy, v. 13, 1984, p. 343-73.

PLONSKI, Guilherme Ary. Inovando métodos na educação continuada dos engenheiros de produção. Revista Produção (Online), v.2, n.1, São Paulo. Jun/1992. Disponível em: <http://dx.doi.org/10.1590/S010365131992000100006 >. Acesso em: 30 ago. 2016.

POSSAS, Mario Luiz. Instituto de Economia 75 anos: Palestra Mario Possas, Perspectivas Econômicas. 12 maio 2014. Disponível em: <https://www.youtube.com/watch?v=xR2dJySknL0>. Acesso em: 30 out. 2015.

SANTANA, Jaciane Freire; GARCIA, Joana Coeli Ribeiro; TELES, Lorena; AGUIAR, Niliane. Políticas públicas de acesso à informação científica: Portal de Periódicos da Capes. Encontros Bibli: revista eletrônica de biblioteconomia e ciência da informação, v. 17, 2012, n. 35, 121-144. Disponível em: $<$ http://goo.gl//rOpVE>. Acesso em: 02 abr 2016.

SCIELO - 15 Anos de Acesso Aberto: um estudo analítico sobre Acesso Aberto e comunicação científica. Paris: UNESCO: 2014. 188 p. Disponível em: <http://dx.doi.org/10.7476/9789237012376>. Acesso em: 26 abr. 2016.

SOUZA, J. H. Os núcleos de articulação com a indústria: um instrumento de política tecnológica para o setor de bens de capital. Dissertação (Mestrado). Instituto de Geociências, Universidade Estadual de Campinas, Campinas, 1977. 